Research Article

\title{
Effect of Drainage and Consolidation on the Pore Water Pressures and Total Stresses within Backfilled Stopes and on Barricades
}

\author{
El Mustapha Jaouhar and Li Li i \\ Research Institute on Mines and Environment, Department of Civil, Geological and Mining Engineering, \\ École Polytechnique de Montréal, C.P. 6079, Succursale Centre-Ville, Montréal, QC, Canada H3C 3A7
}

Correspondence should be addressed to Li Li; li.li@polymtl.ca

Received 2 January 2019; Revised 24 March 2019; Accepted 2 April 2019; Published 12 May 2019

Academic Editor: Jian Ji

Copyright (C) 2019 El Mustapha Jaouhar and Li Li. This is an open access article distributed under the Creative Commons Attribution License, which permits unrestricted use, distribution, and reproduction in any medium, provided the original work is properly cited.

The pore water pressures (PWPs) and total stresses during the placement of a slurried backfill in underground mine stopes are the key parameters for the design of barricades, built to retain the backfill in the stopes. They can be affected by the drainage and consolidation of the backfill. Over the years, several studies have been reported on the pressure and stresses in backfilled stopes by accounting for the drainage and consolidation. Most of them focused on the pressure and stresses in the stopes, few specifically on the barricades. The effect of the number of draining holes commonly installed through the barricade has never been studied. In this paper, the influence of hydraulic properties and filling rate of the backfill, stope size, barricade location, and number of draining holes is systematically investigated with numerical simulations. The results show that the stresses in the backfilled stope and on the barricade largely depend on the filling rate, hydraulic conductivity, and Young's modulus of the backfill. The draining holes can significantly decrease the PWP, but only slightly the total stresses on the barricades in short term.

\section{Introduction}

The mining industry produces large amounts of tailings that require proper management. Among the various disposal techniques available, the use of tailings as filling material in underground openings has become a common practice in mines worldwide. Stope backfilling reduces the amount of mine wastes disposed at the surface, so it can be considered an environmentally friendly solution for mine waste management [1-5]. Other benefits from the mining stope backfilling include improved ground stability, reduced subsidence and ore dilution, increased ore recovery, and improved efficiency of ventilation (e.g., [6]).

Depending on their source and material properties, mine backfills are generally classified as rockfill, hydraulic backfill, and paste backfill. Paste backfill (PB) has been gaining popularity for decades due in part to the use of all-coming tailings (i.e., full tailings), relative ease of pipe transportation, and segregation-less deposition. As it contains a large portion of fine particles, $\mathrm{PB}$ is characterized by a low hydraulic conductivity. Sufficient proportion of water is needed in $\mathrm{PB}$ to facilitate transportation. Its deposition in stopes is usually accompanied by the generation of excess pore water pressure (PWP), followed by dissipation during drainage and self-weight consolidation of the backfill [7]. The pressures applied by the backfill can become critically high, so the retaining barricade constructed at the base of a stope may fail and lead to undesirable consequences [8-12].

For the stability analysis and design of barricades, it is very important to understand that the determining parameters are the peak values of the PWP and total stresses exercised by the slurried backfill on the barricade. A common practice to design barricades is to consider the pressures dues to the fill overburden, without considering arching effect associated with stress transfer from the backfill to the walls. This solution may lead to an overly conservative estimate of the maximum allowed height of backfill to ensure barricade stability. For most cases, the backfilling placement has to be divided into a plug pour and a final pour, with an interval of one or two days between the two placement 
stages. This backfilling interruption is undesirable because it affects the productivity and can cause pipe blockage [13]. Consequently, mining operators would prefer continuous stope backfilling. One must then have a good understanding and knowledge of the stress state within the stope and on the barricades during and after the placement of the backfill. This requires an assessment of the coupled processes that involve generation of excess PWP due to the addition of new backfill layers and their dissipation within the newly and previously deposited layers. These coupled processes are known as the drainage and consolidation of the slurried backfill [14-18].

The output flowrate of the backfill pipe is controlled by the production capacity of backfill plant, the size of main backfill transportation pipes, and the number of stopes to be simultaneously backfilled. These also control the rising rate of the backfill, which is inversely proportional to the horizontal cross-sectional area of the stope. In practice, filling a stope may take several days. Excess PWP can then be generated during the addition of backfill. Drainage and consolidation of the backfill also occur during the filling operation at a rate depending on the hydraulic properties, filling rate, stope, and drift geometries, and efficiency of the drainage system (usually through the barricade). The PWP and stresses can thus become smaller than those based on the isogeostatic overburden pressure.

Over recent years, several papers have been published on the effect of cementation (cement hydration) or selfdesiccation of cemented backfill on the pressures in backfilled stopes. Cement hydration consumes water and makes the backfill harder and stronger. These double effects may considerably decrease the PWP in the backfilled stope [19]. However, it is important to note that the peak values of the PWP and total stresses only occur during the filling operation. For the stability analysis and design of barricades, the most critical moment is during the stope filling operation. When the cement content of the backfill is high (more than $7 \%$ ), the cementation can take place during the filling operation and reduces the PWP and total stresses. For most cases, especially for open stoping methods, the cement content is low, typically between 3 and $7 \%$. It is conservative to neglect the effect of cementation for the design of barricades. In this study, only the drainage and consolidation of slurried backfill are considered in the estimation of the pressure and stresses in backfilled stopes and on barricades.

Over the years, much work has been conducted to assess the stresses in backfilled stopes through analytical solutions [20-28], experimental measurements [7, 27, 29-31], and numerical calculations [32-35]. The stress distribution in drift and on barricades has also be analysed by $\mathrm{Li}$ and Aubertin [36]. These investigations on the stress state within backfilled stopes have highlighted the development of arching effect due to stress redistribution along the rock walls. Progressive filling, drainage, and consolidation of the backfill were however neglected in most of these studies.

Over the years, a few studies have been reported on the analyses of pressure and stresses in backfilled stopes by accounting for the drainage and consolidation [14-18, 37, 38]. The influence of the filling rate and fill proprieties was considered $[18,38,39]$. Most of them focused on the PWP and stresses in the backfilled stopes. Very few investigations were specifically devoted to the pressure and stresses on the barricades. Subsequently, several aspects controlling the drainage and consolidation were neglected in previous studies. These include, for example, the size of the drift cross section (smaller than that of the stope) and barricade location. In addition, draining holes are commonly installed through barricades to accelerate the drainage and consolidation. However, the influence of the number of draining holes on the PWP and total stresses has never been studied.

In this paper, these never-investigated influencing factors are addressed. The PWP and total and effective stresses in backfilled stopes and on barricades are analysed here based on numerical modeling, considering representative stope and drift geometries, backfill (PB) hydrogeotechnical properties, filling rates, and drainage conditions.

\section{Numerical Models}

The SIGMA/W plane strain (2D) finite element program [40] has been used to simulate the hydrogeotechnical response of the PB progressively deposited in stopes. The validation of SIGMA/W on the analyses of stress-strain and drainage and consolidation against analytical solutions has been reported in several theses [22, 41-43]. An example of validation of SIGMA/W on drainage and consolidation analysis is illustrated in Appendix [42]. The applicability of SIGMA/W on such analysis has been tested by numerically reproducing some experimental results obtained by laboratory tests under controlled conditions $[17,22,41]$.

Figure 1(a) shows schematically a backfilled stope with a barricade at the base of the stope, in the drawpoint drift. The stope has a width $B$ and a length $L$ (all sizes in meters). It is backfilled to a height $H$ by progressive deposition of a PB. The drift has a width $B_{\mathrm{d}}$ and a height $H_{\mathrm{d}}$. The barricade has the same width and height as the drift; it is positioned at a distance of $L_{\mathrm{d}}$ from the stope entrance.

The reference (base) model represents a vertical stope $6 \mathrm{~m}$ wide and $20 \mathrm{~m}$ long, backfilled to a height of $30 \mathrm{~m}$. The drift has a height of $5 \mathrm{~m}$ and a width of $5 \mathrm{~m}$. The barricade is built at a distance of $3 \mathrm{~m}$ from the stope entrance.

Figure 1(b) shows a numerical model with some details about the location of the monitoring profiles and draining holes. Figure 1(c) shows a part of the backfilled stope, where the meshes were made by considering three zones: drift, lower portion, and upper portion of the stope. The sensitivity analysis of mesh has been done to ensure stable numerical results [42]. Square elements of $0.1 \times 0.1 \mathrm{~m}$ were used for the backfill in the drift. The backfill in the lower portion (height of $5 \mathrm{~m}$ ) of the stope was represented by rectangular elements $0.2 \mathrm{~m}$ wide and $0.1 \mathrm{~m}$ high, while the backfill in the upper portion of the stope is analysed with rectangular elements $0.4 \mathrm{~m}$ wide and $0.2 \mathrm{~m}$ high.

The backfill is considered as elastic-plastic obeying the Mohr-Coulomb criterion. The fill proprieties are characterized by its saturated unit weight $\left(\gamma_{\text {sat }}\right)$, Young's modulus $(E)$, Poisson's ratio $(\mu)$, internal friction angle $(\phi)$, cohesion 


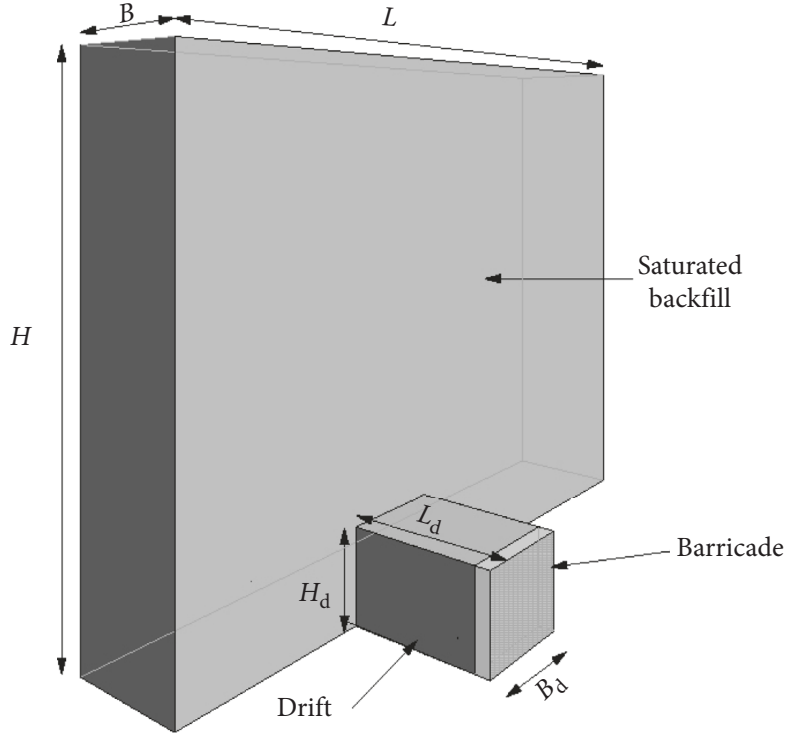

(a)

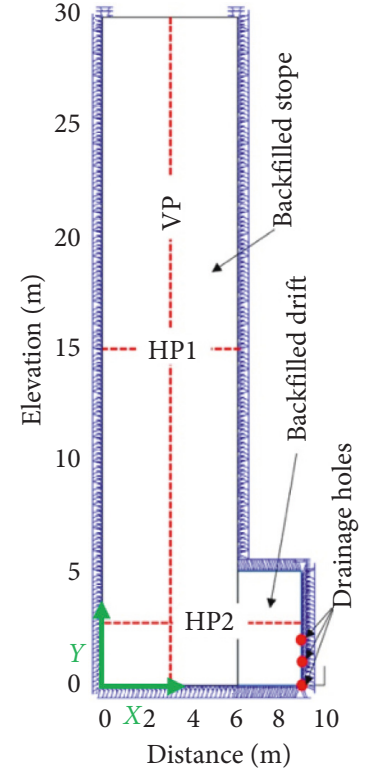

(b)

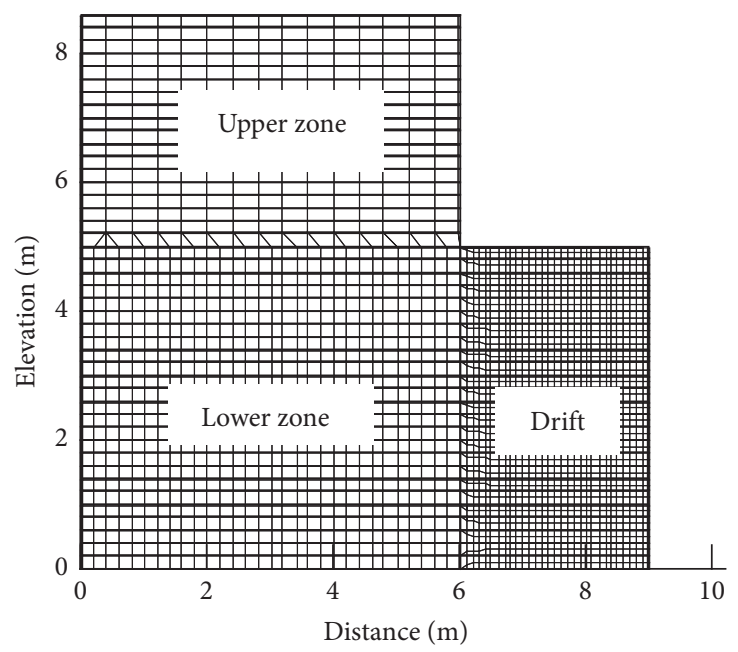

(c)

FiguRE 1: (a) A typical vertical backfilled stope with a drift and a barricade; (b) numerical model of the backfilled stope; (c) mesh zones near the base of the stope.

$(c)$, dilation angle $(\psi)$, and hydraulic conductivity $\left(k_{\text {sat }}\right)$. In this study, the value of Poisson's ratio $(\mu)$ is associated with the internal friction angle $(\phi)$ as follows [32, 44-47]:

$$
\mu=\frac{1-\sin \phi}{2-\sin \phi}
$$

The following values were used in the reference case: $E=300 \mathrm{MPa}, c=0 \mathrm{kPa}, \psi=0^{\circ}$, and $\phi=30^{\circ}$; equation (1) gives $\mu=0.333$. These values as well as the hydraulic conductivity (see text below) are taken in the range of available data reported in the literature $[29,48]$.

Drifts usually have a smaller width $B_{\mathrm{d}}$ compared to the stope length $L$. With a $2 \mathrm{D}$ (plane strain) model, both the stope and drift are simulated as infinitely long in the third dimension. For such cases, the draining capacity through the drift (backfill) will be overestimated. To overcome this problem, the saturated hydraulic conductivity of the backfill in the drift $k_{\text {sat_d }}$ is reduced as follows:

$$
k_{\text {sat_d }}=k_{\text {sat }} \frac{B_{\mathrm{d}}}{L} \text {. }
$$

For the reference (base) case, the backfill in the stope has a hydraulic conductivity of $k_{\mathrm{sat}}=10^{-7} \mathrm{~m} / \mathrm{s}$. Equation (2) with $B_{\mathrm{d}}=5 \mathrm{~m}$ and $L=20 \mathrm{~m}$ gives $k_{\text {sat d }}=2.5 \times 10^{-8} \mathrm{~m} / \mathrm{s}$ for the corrected hydraulic conductivity of the backfill in the drift.

Figure 2 shows the variation of the volumetric water content as a function of the suction in the unsaturated backfill (after drainage) (Figure 2(a)) and the corresponding hydraulic conductivity function (Figure 2(b)), based on experimental results provided by Aubertin et al. [49], Bussière [50], and Godbout et al. [48]. Figure 2(c) shows the 


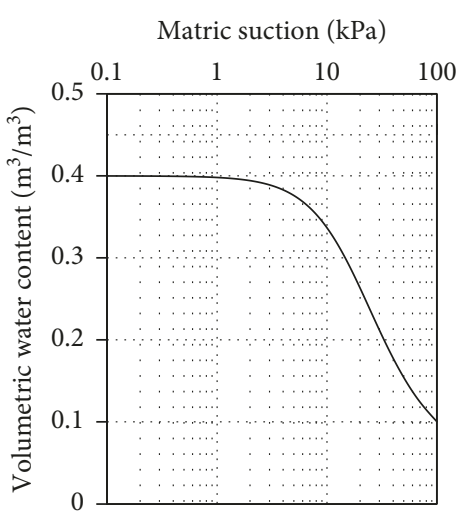

(a)

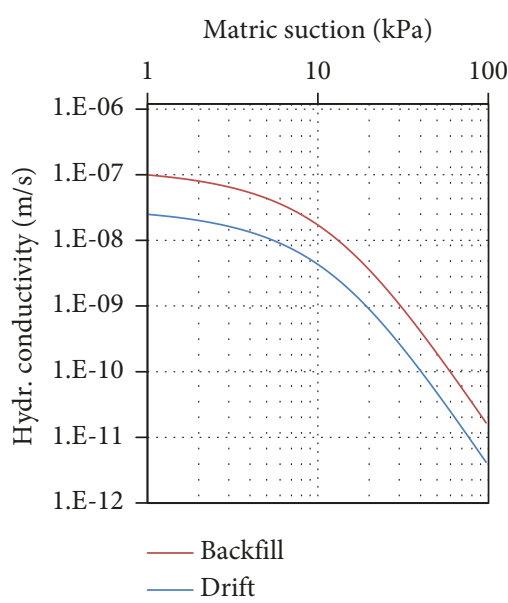

(b)

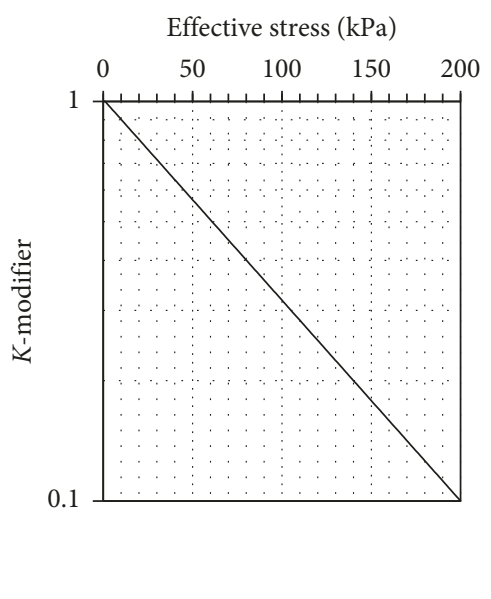

(c)

FIGURE 2: Hydraulic properties applied to the unsaturated backfill and interface elements: (a) water retention curve of the backfill; (b) hydraulic conductivity function for the backfill in the stop and in the drift; (c) $k$-modifier function which is applied on the $k$ function following backfill consolidation.

$K$-modifier which changes the value of $k$ as a function of the vertical effective stresses (based on experimental results obtained by Fahey et al. [14]; this effect is due to the reduction of the backfill void ratio with consolidation.

Progressive filling of the stope is simulated by adding successive layers of backfill on the top of previously deposited fill. In practice, the filling rate of $\mathrm{PB}$ usually varies from about 0.2 to $0.4 \mathrm{~m} / \mathrm{h}$ [7]. For the reference case, a filling rate of $0.3 \mathrm{~m} / \mathrm{h}$ is applied. The progressive increase of backfill height is simulated by the instantaneous addition of a backfill layer of $0.2 \mathrm{~m}$ (in thickness) every 40 minutes. Drainage and consolidation of the newly placed and previously deposited backfill take place continuously.

Regarding the mechanical boundary conditions (Figure 1(b)), the rock walls are fixed in the vertical and horizontal directions. The barricade, represented by a rigid face, is equally fixed in both directions. The hydraulic boundary conditions include a top backfill surface simulated as an impervious face (further addressed in Discussion), two water-proof side walls, an impervious base, and a waterproof barricade. Draining holes (three for the reference case) spaced at $1 \mathrm{~m}$ in the vertical direction, with a nil pore water pressure, are included in the barricade.

Table 1 presents the various cases simulated for analyzing the influence of the different parameters on the stresses and PWPs evolution in the stope and on the barricade.

As reported by El Mkadmi et al. [39] and Sobhi [43], SIGMA/W sometimes tends to underestimate the vertical stresses in backfilling stopes (compared to analytical solutions and other codes such as FLAC of Itasca). Thin vertical elements have been added along the two fill-rock interfaces in SIGMA/W to reduce this effect. These elements have the same mechanical properties as the backfill, except for Young's modulus of the backfill adjusted to a lower value so the stresses obtained with SIGMA/W (with interface elements) are close to those obtained by FLAC (without
TABLE 1: Characteristics of the numerical simulations with the various parameters used (with $\gamma_{\text {sat }}=20 \mathrm{kN} / \mathrm{m}^{3}, \mu$ defined by equation (1), and $H=30 \mathrm{~m}$ ).

\begin{tabular}{lcccccccc}
\hline Cases & $B$ & $E$ & $\phi$ & \multicolumn{2}{c}{$k_{\text {sat }}(\mathrm{m} / \mathrm{s})$} & $V$ & $L_{\mathrm{d}}$ \\
& $(\mathrm{m})$ & $(\mathrm{MPa})$ & $\left({ }^{\circ}\right)$ & Stope & Drift & $(\mathrm{m} / \mathrm{h})$ & $n_{\mathrm{d}}$ & $(\mathrm{m})$ \\
\hline 0 (base) & 6 & 10 & 30 & $10^{-7}$ & $2.5 \times 10^{-8}$ & 0.3 & 3 & 3 \\
1 & Var & 10 & 30 & $10^{-7}$ & $2.5 \times 10^{-8}$ & 0.3 & 3 & 3 \\
2 & 6 & 10 & 30 & Var & Var & 0.3 & 3 & 3 \\
3 & 6 & 10 & 30 & $10^{-7}$ & $2.5 \times 10^{-8}$ & Var & 3 & 3 \\
4 & 6 & 10 & 30 & $10^{-7}$ & $2.5 \times 10^{-8}$ & 0.3 & Var & 3 \\
5 & 6 & 10 & Var & $10^{-7}$ & $2.5 \times 10^{-8}$ & 0.3 & 3 & 3 \\
6 & 6 & 10 & 30 & $10^{-7}$ & $2.5 \times 10^{-8}$ & 0.3 & 3 & Var \\
7 & 6 & Var & 30 & $10^{-7}$ & $2.5 \times 10^{-8}$ & 0.3 & 3 & 3 \\
\hline
\end{tabular}

$V(\mathrm{~m} / \mathrm{h})$, average filling rate; $n_{\mathrm{d}}$, number of draining holes; $L_{\mathrm{d}}(\mathrm{m})$, position of the barricade; Var, variable.

interface elements). This adjustment process led to a variation of Young's modulus of the vertical interface elements as a function of the (vertical) effective stress, as shown in Figure 3. A good agreement has then been achieved between the stresses obtained by SIGMA/W (with weaker vertical elements) and FLAC (without interface elements) for different stope geometries and backfill proprieties; more details and results have been presented by Jaouhar [42].

\section{Numerical Simulation Results}

Generation of excess PWP due to addition of new backfill layers and dissipation of PWPs within the backfill due to drainage and consolidation has been simulated. The evolution of PWPs and stresses along a vertical profile (VP) located at a distance of $2.8 \mathrm{~m}$ from the left wall, a horizontal profile (HP1) at midheight of the stope (15 $\mathrm{m}$ from the base), and a second horizontal profile (HP2) at midheight of the drift (2.6 from the base of the drift) is examined in the following (see Figure 1(b) for the locations). 


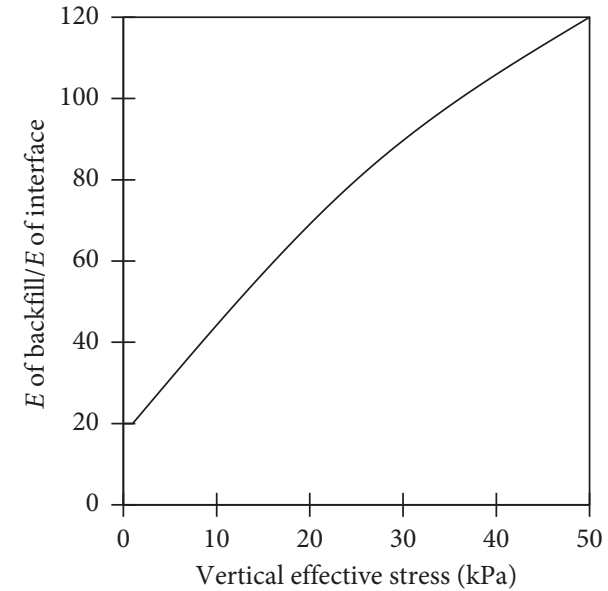

FIgURE 3: Young's modulus of the backfill in the thin vertical elements along the walls adjusted as a function the vertical effective stress.

Figure 4 shows the evolution of the horizontal $\left(\sigma_{\mathrm{h}}\right)$ (Figure $4(\mathrm{a})$ ) and vertical $\left(\sigma_{\mathrm{v}}\right)$ (Figure $4(\mathrm{~b})$ ) total stresses and PWP $\left(u_{\mathrm{w}}\right)$ (Figure $4(\mathrm{c})$ ) along the VP during backfill deposition for the reference (base) case. It is seen that the total stresses and PWP tend to increase almost linearly as filling progresses. Near the end of the filling operation, the distribution of the stresses and PWP become nonlinear, indicating the occurrence of drainage and self-weight consolidation of the backfill.

Figure 5 presents the evolution of the horizontal $\left(\sigma_{\mathrm{h}}\right)$ (Figure 5(a)) and vertical $\left(\sigma_{\mathrm{v}}\right)$ (Figure 5(b)) total stresses along the VP after deposition of the last $\left(150^{\text {th }}\right)$ backfill layer for the reference (base) case. As can be seen, drainage and dissipation of the PWP after the final layer deposition tend to induce nonlinear and decreasing horizontal stresses, which progressively become smaller than the vertical (total) stresses particularly near the base of the stope. The initial isogeostatic overburden pressure at the base of the stope is $\sigma_{\mathrm{v}}=\sigma_{\mathrm{h}}=20 \mathrm{kN} / \mathrm{m}^{3} \times 30 \mathrm{~m}=600 \mathrm{kPa}$; the numerical simulation shows an initial vertical (total) stress $\sigma_{\mathrm{v}}$ of about $560 \mathrm{kPa}$ and a horizontal stress $\sigma_{\mathrm{h}}$ of $523 \mathrm{kPa}$. This relatively small difference indicates the short-time occurrence of drainage and consolidation, accompanied by the dissipation of the excess PWP and development of effective stresses $\left(\sigma_{\mathrm{v}}^{\prime}\right.$ and $\sigma_{\mathrm{h}}^{\prime}>0$ ).

The vertical distribution and evolution of the PWP $\left(u_{\mathrm{w}}\right)$ along the VP is shown in Figure 5(c) after the deposition of the last layer of backfill. At time zero (just after deposition of this last layer), the PWP is equal to about $488 \mathrm{kPa}$ at the base of the stope; this value is much lower than the (theoretical) isogeostatic overburden pressure of $600 \mathrm{kPa}$. The difference indicates that drainage and consolidation occurred on the backfill during filling of the stope (over a period of 100 hours). With longer time, the PWP and total stresses generally decrease along the height of the stope, except near the top of the backfill where one sees slight increase in the PWP and total stresses. Similar results have been reported in El Mkademi et al. [39]. These increases are interpreted as ponding due to accumulation of water on the top of the backfill associated with the upward drainage. These results along with the hydraulic boundary condition imposed along the top surface of the backfill will be later discussed in Discussion.

Figure 6 shows the evolution of the horizontal $\left(\sigma_{\mathrm{h}}\right)$ (Figure 6(a)) and vertical $\left(\sigma_{\mathrm{v}}\right)$ (Figure 6(b)) total stresses and the PWP $\left(u_{\mathrm{w}}\right)$ (Figure 6(c)) after deposition of the last $\left(150^{\text {th }}\right)$ backfill layer, along the line HP1 for the reference (base) case (Figure 1(b)). At the beginning after the end of the filling operation, the PWP and the horizontal and vertical stresses at midheight of the stope are initially quite close but slightly lower than the isogeostatic overburden stresses $(300 \mathrm{kPa})$, indicating a rapid occurrence of backfill drainage and consolidation. The values of $u_{\mathrm{w}}, \sigma_{\mathrm{h}}$, and $\sigma_{\mathrm{v}}$ then progressively decrease with time. The PWP $\left(u_{\mathrm{w}}\right)$ and the horizontal total stress $\left(\sigma_{\mathrm{h}}\right)$ tend to become uniform across the stope width, while the vertical total stress $\left(\sigma_{\mathrm{v}}\right)$ takes a smaller value near the walls than along the center line of the stope.

The evolution of the PWP and total stresses along HP2 (midheight of the drift, (Figure 1(b)) after the last backfill layer deposition is presented in Figure 7. There is a slight decrease in the PWP and total stresses from the stope toward the barricade. These results reflect the effect of drainage (through draining holes) across the barricade. After 18 days, the horizontal total stress $\sigma_{\mathrm{h}}$ is reduced to two-thirds of its initial value, while the PWP has decreased to half of its initial value.

It is interesting to note that the vertical total stress shows an increase trend near the barricade. In the stope, similar trend can be observed in the horizontal stress near the bottom of the stope, as shown in Figure 5(a) or elsewhere in published papers (e.g., $[33,51])$. This phenomenon, known as "kinks," has been explained by the restriction of vertical movement of the backfill near the bottom of the stope [52]. In the drift, arching can take place in the horizontal direction because the backfill in the drift is pushed and compressed by the backfill in the stope [36]. The horizontal movement of the backfill in the drift is restricted by the barricade, resulting in occurrence of "kinks" and increase of the stress perpendicular to the arching direction. This explains well the increase of the vertical total stress near the barricade, as shown in Figure 7(b).

Figure 8 shows the evolution of the PWP and total stresses along the barricade height (at a distance of $4 \mathrm{~cm}$ from the barricade) after the end of filling operation. The PWP and total stresses increase with the depth above the draining holes, but decrease with the depth below the top draining hole. The peak value of the PWP decreases from $400 \mathrm{kPa}$ at the end of the filing operation to $185 \mathrm{kPa}$, while the peak value of the horizontal total stress decreases from $479 \mathrm{kPa}$ to $289 \mathrm{kPa}$ after a repose period of 18.2 days. The effect of the draining holes in reducing the barricade load is well demonstrated.

\subsection{Parametric Analyses for Different Influence Factors.} The evolution of the total stresses and PWP in the stope and drift has been presented above for the reference case. The effect of various influencing factors on the total stresses and 

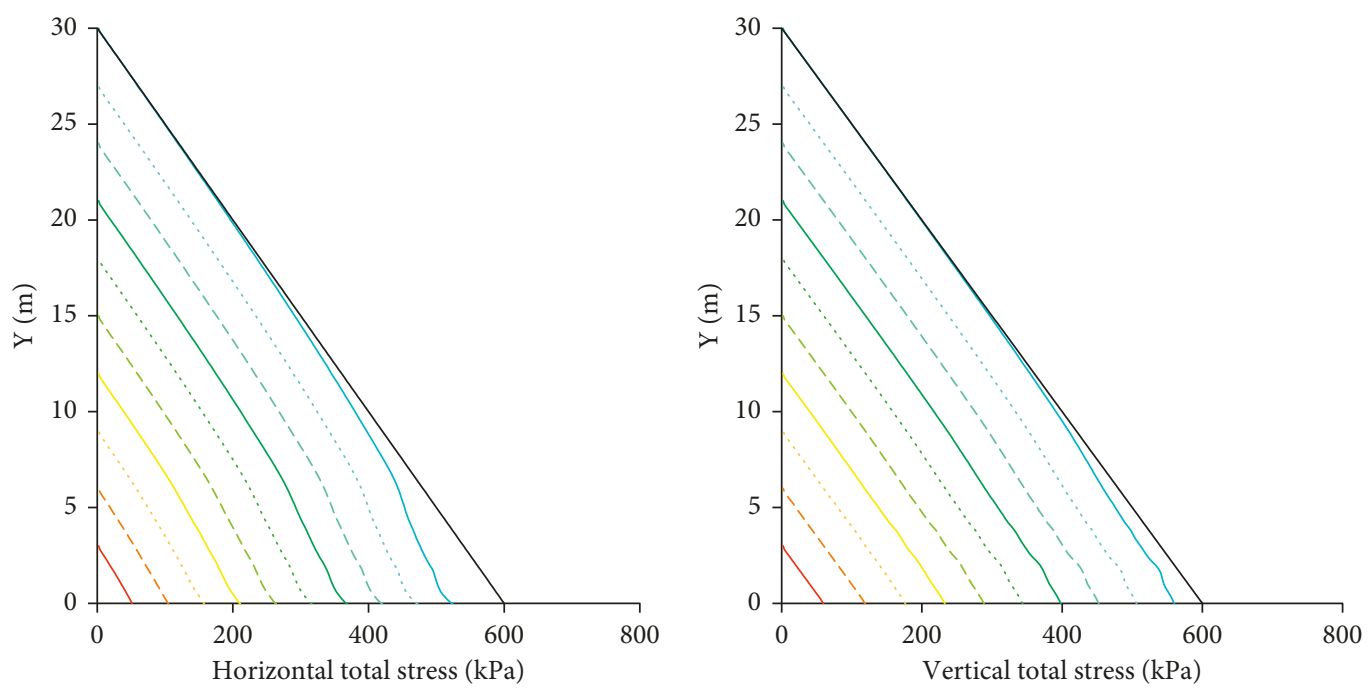

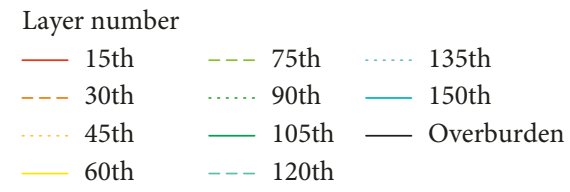

(a)

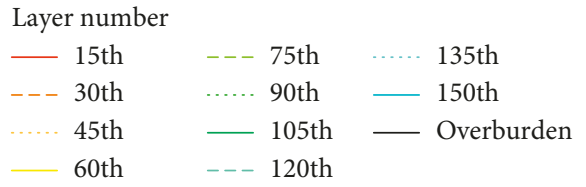

(b)

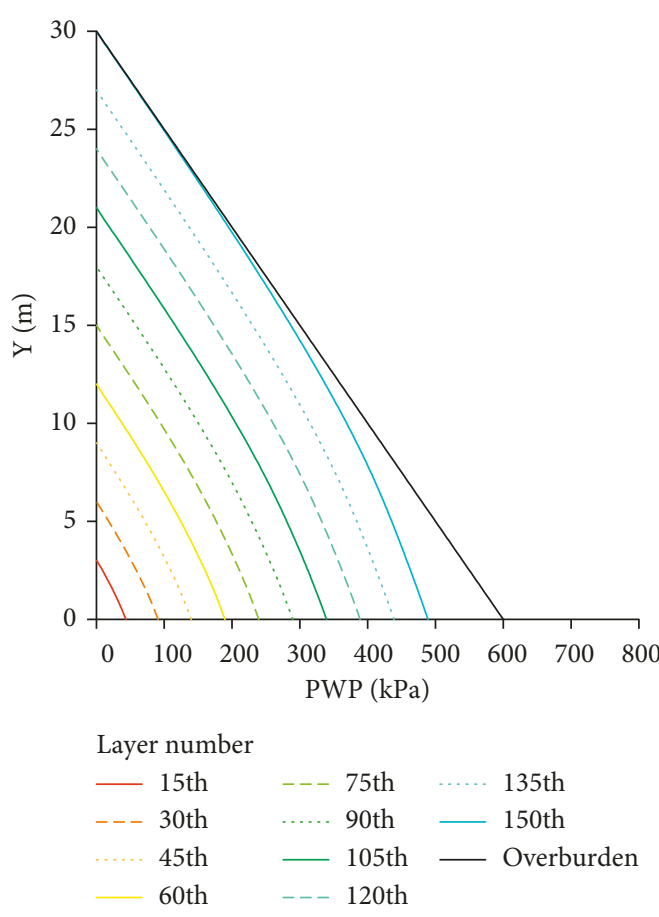

(c)

Figure 4: Evolution of the (a) horizontal $\left(\sigma_{\mathrm{h}}\right)$ and $(\mathrm{b})$ vertical $\left(\sigma_{\mathrm{v}}\right)$ total stresses and $(\mathrm{c})$ the PWP $\left(u_{\mathrm{w}}\right)$ along the vertical profile $(\mathrm{VP})$ during filling of the stope with 150 layers of backfill (reference case, see details in Table 1, Case 0 ).

pressures is presented in the following subsections. These include stope width $(B)$, backfill saturated hydraulic conductivity $\left(k_{\text {sat }}\right)$, internal friction angle $(\phi)$, Young's modulus $(E)$, filling rate $(V)$, the number of draining holes $\left(n_{\mathrm{d}}\right)$ in the barricade, and the position of the barricade $\left(L_{\mathrm{d}}\right)$. These simulated cases are detailed in Table 1.
3.1.1. Stope Width B. Figure 9 shows the evolution of $\sigma_{\mathrm{h}}$ (Figure 9(a)) and $u_{\mathrm{w}}$ (Figure 9(b)) at midheight on the barricade, from the start of backfilling for stopes having a width of 3,6, and $9 \mathrm{~m}$. Both the horizontal total stress and PWP reach a peak value after about 4.14 days from the beginning of stope filling, independently on the stope width; 

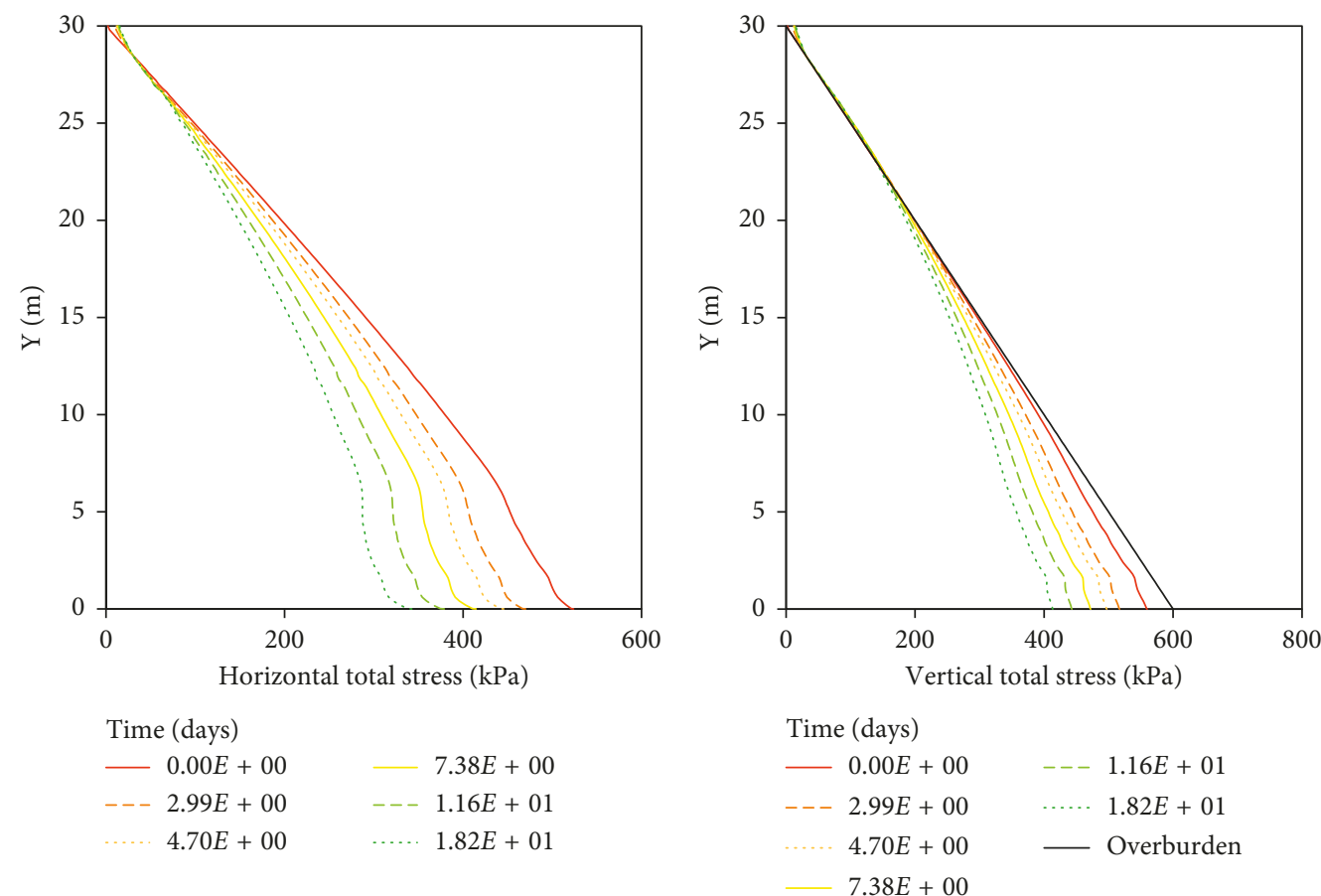

(a)

(b)

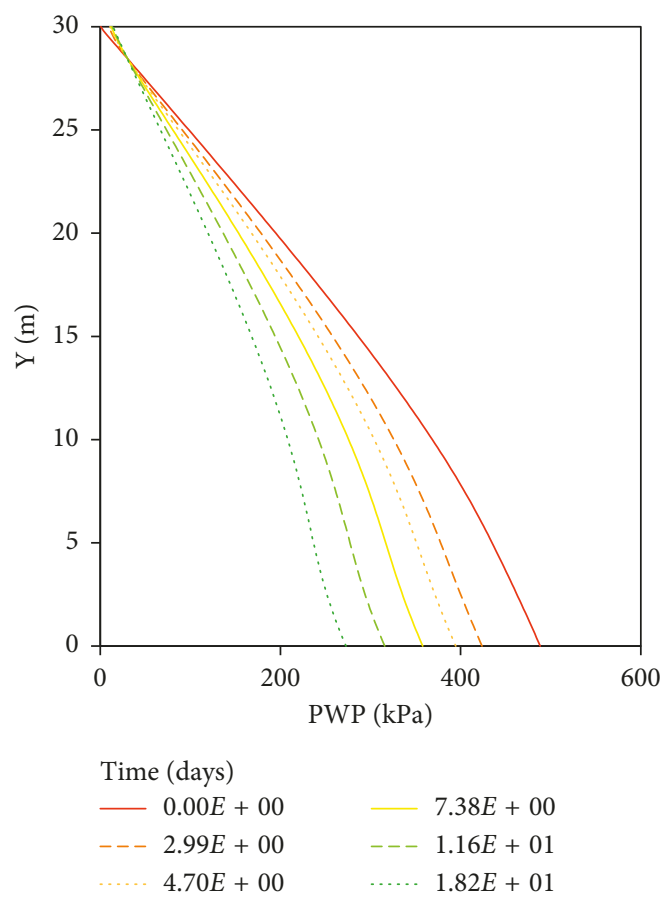

(c)

Figure 5: Evolution of the (a) horizontal $\left(\sigma_{\mathrm{h}}\right)$ and $(\mathrm{b})$ vertical $\left(\sigma_{\mathrm{v}}\right)$ total stresses and $(\mathrm{c})$ the PWP $\left(u_{\mathrm{w}}\right)$, along the vertical profile VP after the addition of the $150^{\text {th }}$ (last) layer of backfill in the stope for the reference case (see the details in Table 1 , Case 0 ).

the maximum values are $\sigma_{\mathrm{h}}=450 \mathrm{kPa}$ and $u_{\mathrm{w}}=331 \mathrm{kPa}$ for $B=3 \mathrm{~m}, \sigma_{\mathrm{h}}=480 \mathrm{kPa}$ and $u_{\mathrm{w}}=357 \mathrm{kPa}$ for $B=6 \mathrm{~m}$, and $\sigma_{\mathrm{h}}=487 \mathrm{kPa}$ and $u_{\mathrm{w}}=364 \mathrm{kPa}$ for $B=9 \mathrm{~m}$. After 92 days, the horizontal total stress and PWP on the barricade have decreased to $\sigma_{\mathrm{h}}=130 \mathrm{kPa}$ and $u_{\mathrm{w}}=44 \mathrm{kPa}$ for $B=3 \mathrm{~m}$, $\sigma_{\mathrm{h}}=178 \mathrm{kPa}$ and $u_{\mathrm{w}}=64 \mathrm{kPa}$ for $B=6 \mathrm{~m}$, and $\sigma_{\mathrm{h}}=230 \mathrm{kPa}$ and $u_{\mathrm{w}}=92 \mathrm{kPa}$ for $B=9 \mathrm{~m}$. These results illustrate how the stope width may influence the total stress and PWP on the barricade. Water takes longer time to be drained out through the drift and barricade for wider stopes. 

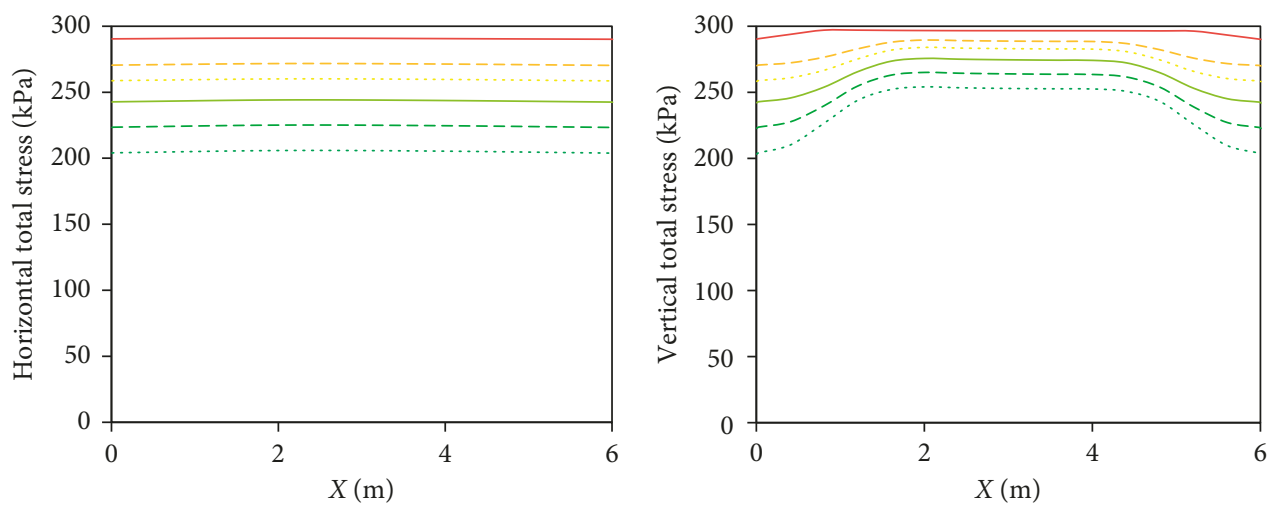

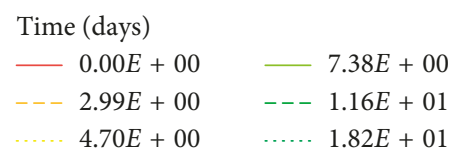

(a)
Time (days)

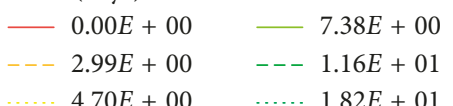

(b)

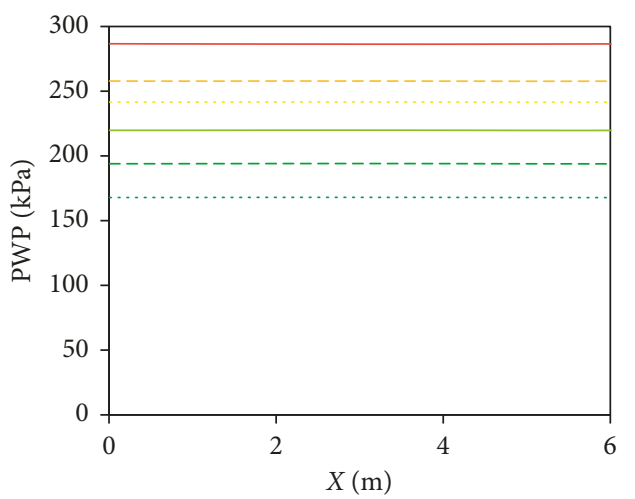

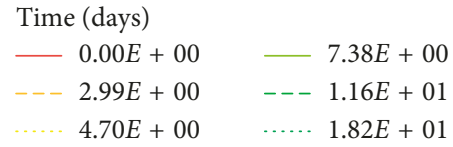

(c)

Figure 6: Evolution of the (a) horizontal $\left(\sigma_{\mathrm{h}}\right)$ and (b) vertical $\left(\sigma_{\mathrm{v}}\right)$ total stresses and (c) PWP $\left(u_{\mathrm{w}}\right)$ along horizontal profile HP1 at midheight of the stope after addition of the last $\left(150^{\text {th }}\right)$ backfill layer for the reference case (see the details in Table 1 , Case 0 ).
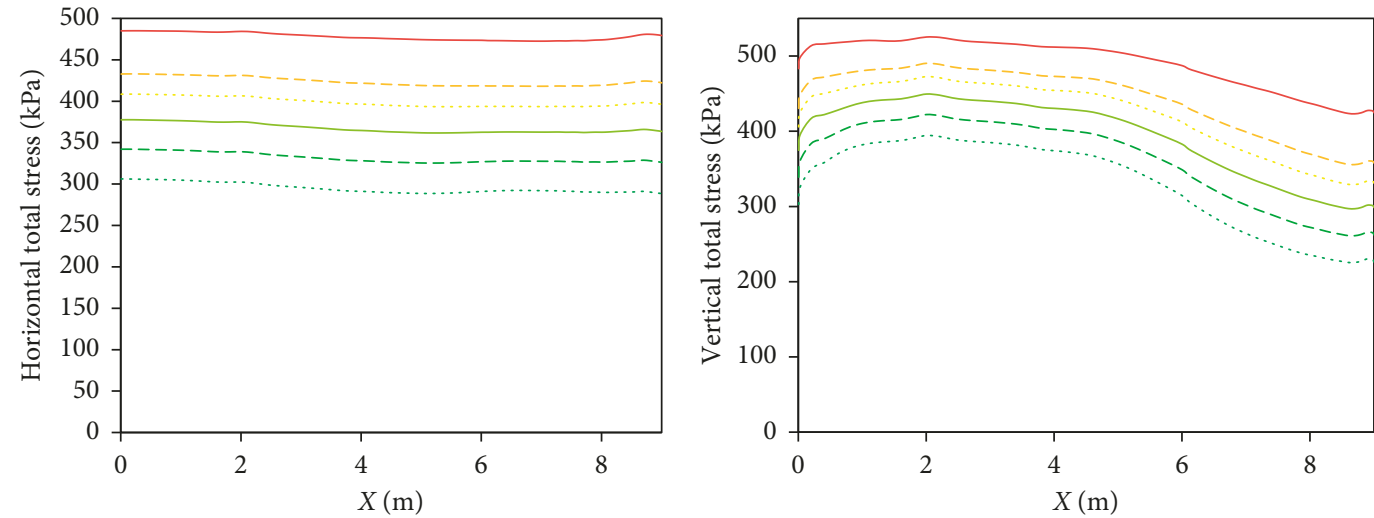

Time (days)

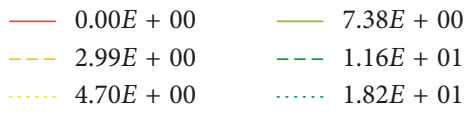

(a)

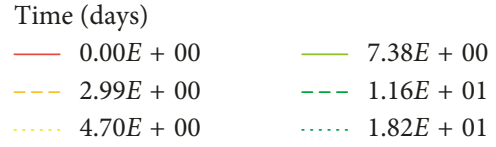

(b)

Figure 7: Continued. 


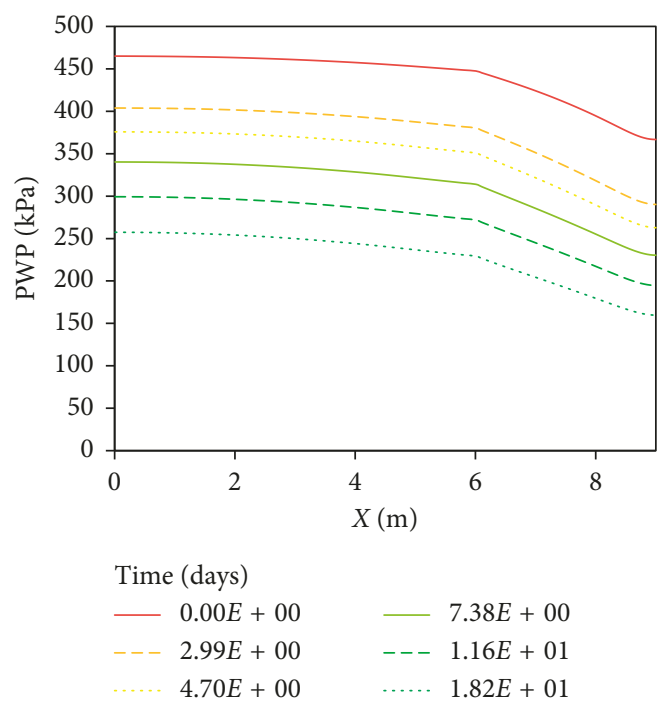

(c)

Figure 7: Evolution of the (a) horizontal $\left(\sigma_{\mathrm{h}}\right)$ and (b) vertical $\left(\sigma_{\mathrm{v}}\right)$ total stresses and (c) the PWP $\left(u_{\mathrm{w}}\right)$, after addition of the $150^{\text {th }}($ last $)$ backfill layer along horizontal profile HP2 at midheight of the drift for the reference case (see the details in Table 1, Case 0).

3.1.2. Hydraulic Conductivity $k_{\text {sat }}$. The hydraulic conductivity varies from $10^{-6}$ to $10^{-5} \mathrm{~m} / \mathrm{s}$ for slurry fills and from $10^{-8}$ to $10^{-6} \mathrm{~m} / \mathrm{s}$ for cemented paste backfill. Figure 10 shows the evolution of the horizontal total stress $\sigma_{\mathrm{h}}$ (Figure 10(a)) and $u_{\mathrm{w}}$ (Figure 10(b)) at midheight of the barricade upon backfill placement for backfill having saturated hydraulic conductivity $k_{\text {sat }}$ of $10^{-8}, 10^{-7}, 10^{-6}$, and $10^{-5} \mathrm{~m} / \mathrm{s}$, respectively. The horizontal total stress and PWP reach peak values after about 4.14 days from the beginning of stope filling, with maximum values of $\sigma_{\mathrm{h}}=289 \mathrm{kPa}$ and $u_{\mathrm{w}}=$ $156 \mathrm{kPa}$ for $k_{\mathrm{sat}}=10^{-6} \mathrm{~m} / \mathrm{s}, \sigma_{\mathrm{h}}=480 \mathrm{kPa}$ and $u_{\mathrm{w}}=357 \mathrm{kPa}$ for $k_{\text {sat }}=10^{-7} \mathrm{~m} / \mathrm{s}$, and $\sigma_{\mathrm{h}}=547 \mathrm{kPa}$ and $u_{\mathrm{w}}=510 \mathrm{kPa}$ for $k_{\mathrm{sat}}=10^{-8} \mathrm{~m} / \mathrm{s}$. After 92 days, the horizontal total stress $\left(\sigma_{\mathrm{h}}\right)$ on the barricade and PWP $\left(u_{\mathrm{w}}\right)$ have decreased to $\sigma_{\mathrm{h}}=138 \mathrm{kPa}$ and $u_{\mathrm{w}}=38 \mathrm{kPa}$ for $k_{\mathrm{sat}}=10^{-6} \mathrm{~m} / \mathrm{s}, \sigma_{\mathrm{h}}=178 \mathrm{kPa}$ and $u_{\mathrm{w}}=64 \mathrm{kPa}$ for $k_{\mathrm{sat}}=10^{-7} \mathrm{~m} / \mathrm{s}$, and $\sigma_{\mathrm{h}}=384 \mathrm{kPa}$ and $u_{\mathrm{w}}=230 \mathrm{kPa}$ for $k_{\mathrm{sat}}=10^{-8} \mathrm{~m} / \mathrm{s}$. These results clearly show that the hydraulic conductivity of the backfill plays a key role in the dissipation of PWPs. PB having hydraulic conductivity typically between $10^{-8}$ and $10^{-7} \mathrm{~m} / \mathrm{s}$ would lead to peak PWPs up to 510 and $357 \mathrm{kPa}$, respectively. With hydraulic backfill having $k_{\text {sat }}$ typically between $10^{-5} \mathrm{~m} / \mathrm{s}$ and $10^{-6} \mathrm{~m} / \mathrm{s}$, much smaller PWP would be resulted on the barricade, with $21 \mathrm{kPa}$ and $156 \mathrm{kPa}$, respectively. These results indicate that hydraulic fills can produce less critical PWP than PB on barricade.

When the backfill has a relatively high hydraulic conductivity of $10^{-5} \mathrm{~m} / \mathrm{s}$, its response becomes quite different from that of a less pervious backfill $\left(\sim 10^{-8} \mathrm{~m} / \mathrm{s}\right)$, as shown in Figure 10. The peak value of $u_{\mathrm{w}}$ is reached later after filling completion of the stope. This can be partly explained by the coupled process of downward drainage at the base of the stope (through the three draining holes) and fast upward drainage during consolidation, resulting in water ponding at the surface of the backfill. However, more work is necessary to understand why the peak values in the PWP and horizontal total stress occur after the end of stope filling operation.

3.1.3. Internal Friction Angle $\phi^{\prime}$. Figure 11 presents the evolution of the horizontal total stress $\sigma_{\mathrm{h}}$ (Figure 11(a)) and PWP $u_{\mathrm{w}}$ (Figure 11(b)) at midheight of the barricade, after the start of stope filling for a backfill internal friction angle $\phi$ of $20^{\circ}, 25^{\circ}, 30^{\circ}, 35^{\circ}$, and $40^{\circ}$; Poisson's ratio $\mu$ also changes as it is related to the value of $\phi$ (equation (1)). The results show that the peak values of the horizontal total stress $\sigma_{\mathrm{h}}$ and PWP $u_{\mathrm{w}}$ are insensitive to this variation of $\phi($ and $\mu)$. Nevertheless, the postpeak values of $\sigma_{\mathrm{h}}$ and $u_{\mathrm{w}}$ tend to decrease as the internal friction angle $\phi$ increases from $20^{\circ}$ to $35^{\circ}$; the differences are more pronounced after about 12 days. Once the internal friction angle $\phi$ is higher than $35^{\circ}$, the PWP and total stresses become again insensitive to the variation of the internal friction angle $\phi$ from $35^{\circ}$ to $40^{\circ}$. This type of responses in total stress has been explained by an increased arching effect with larger $\phi$ [33]; more work is however required to understand this response in the PWP.

3.1.4. Backfill Modulus E. Figure 12 shows the evolution of the horizontal total stress $\sigma_{\mathrm{h}}$ (Figure 12(a)) and PWP $u_{\mathrm{w}}$ (Figure 12(b)) at midheight of the barricade, from the start of backfilling for a backfill modulus $E$ of 10,100 , and $300 \mathrm{MPa}$. At 4.14 days from the beginning of stope filling, peak values are observed for $\sigma_{\mathrm{h}}$ and $u_{\mathrm{w}}$ when the backfill is soft $(E=100 \mathrm{MPa})$ or very soft $(E=10 \mathrm{MPa})$, with maximum values of $\sigma_{\mathrm{h}}=480 \mathrm{kPa}$ and $u_{\mathrm{w}}=357 \mathrm{kPa}$ for $E=10 \mathrm{MPa}$ and $\sigma_{\mathrm{h}}=189 \mathrm{kPa}$ and $u_{\mathrm{w}}=82 \mathrm{kPa}$ for $E=100 \mathrm{MPa}$. With backfill having a typical modulus $E=300 \mathrm{MPa}$, peaks are not well defined on the horizontal total stress and PWP evolution (with $\sigma_{\mathrm{h}} 90 \mathrm{kPa}$ and $u_{\mathrm{w}} 15 \mathrm{kPa}$ ). After these peaks and short 

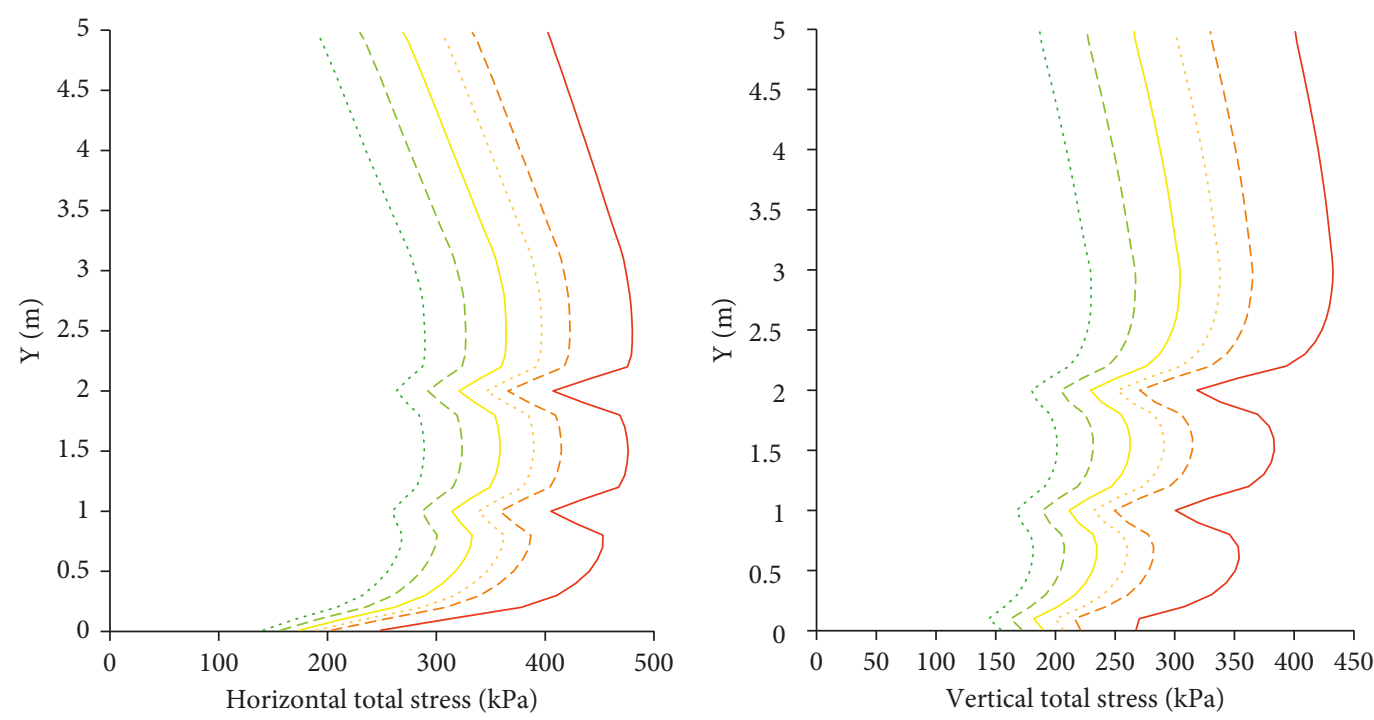

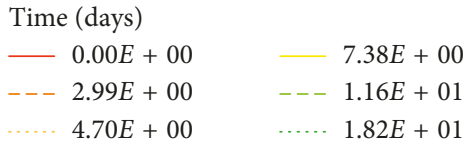

(a)

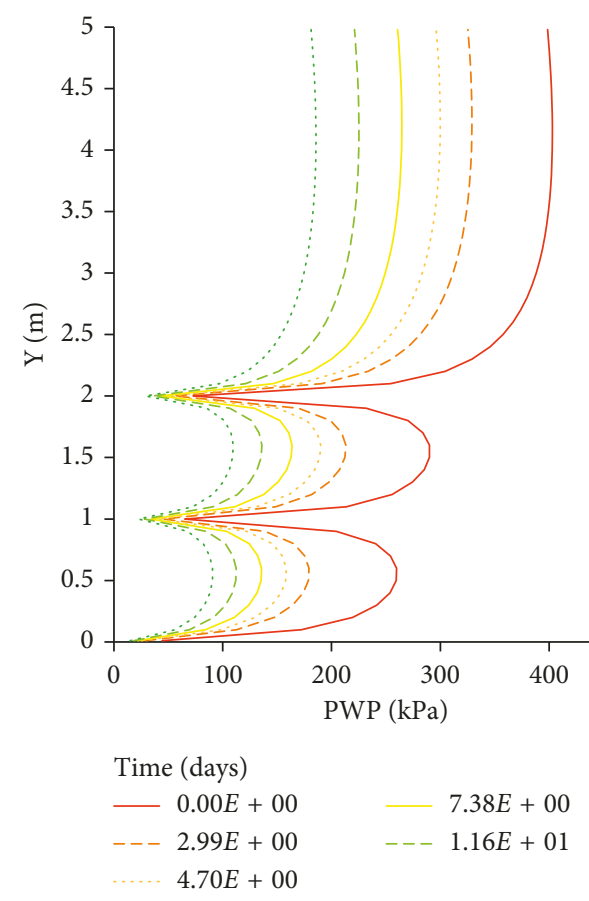

Time (days)

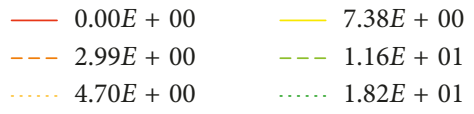

(b)

(c)

FiguRE 8: Evolution of the (a) horizontal $\left(\sigma_{\mathrm{h}}\right)$ and (b) vertical $\left(\sigma_{\mathrm{v}}\right)$ total stresses and (c) PWP $\left(u_{\mathrm{w}}\right)$ along the height of the barricade after the end of stope filling operation for the reference case (see the details in Table 1, Case 0 ).

decrease, the horizontal total stress and PWP begin to increase and jump at around 18.7 days and stabilize at $\sigma_{\mathrm{h}}=150 \mathrm{kPa}$ and $u_{\mathrm{w}}=45 \mathrm{kPa}$.

These results indicate that the stiffness of the backfill may significantly influence the maximum total stress and PWP exerted by the backfill on the barricade. With a stiffer backfill, the deformability and compressibility are lower. There will be less water drained by consolidation. It is thus advantageous to use stiffer backfill to reduce loads on barricades. Optimization should however consider the backfill transportation requirement and barricade construction costs. 


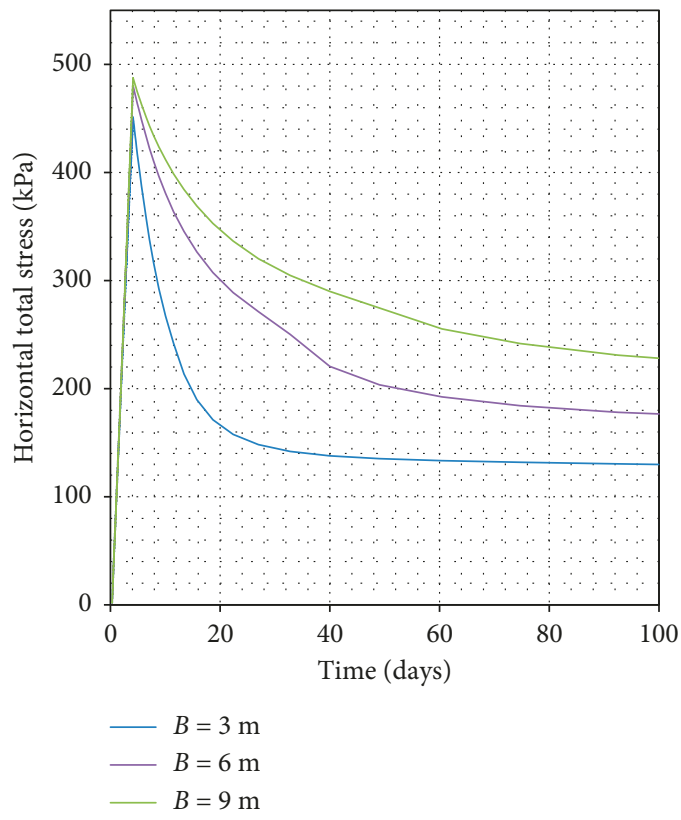

(a)

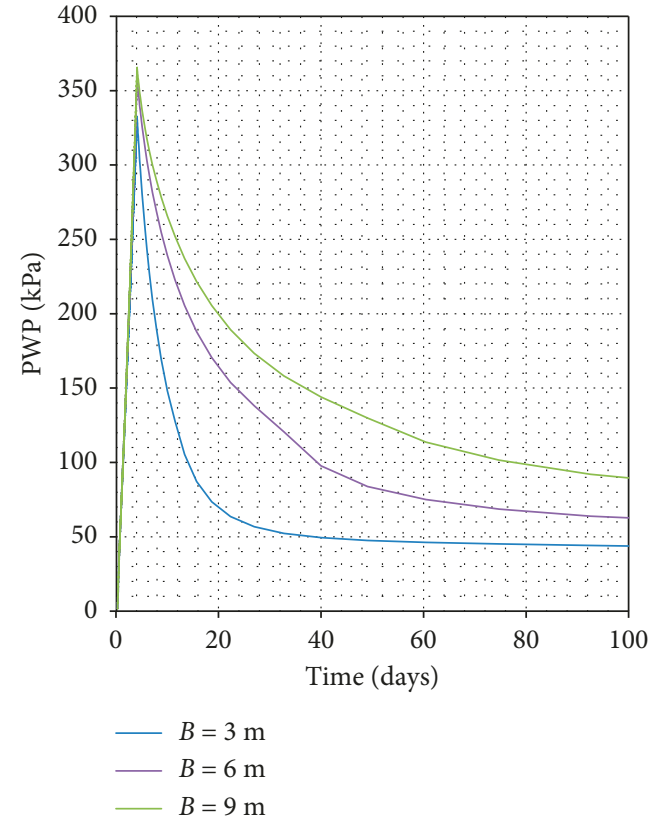

(b)

FIgURE 9: Evolution of (a) $\sigma_{\mathrm{h}}$ and (b) $u_{\mathrm{w}}$ on the barricade at midheight of the drift for three different stope widths (see the details in Table 1, Case 1).

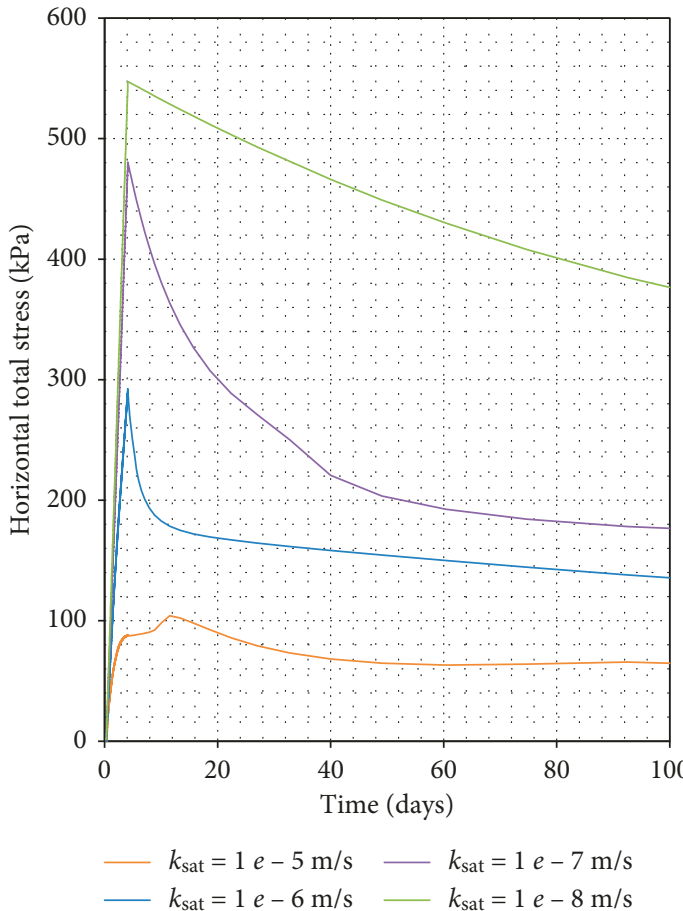

(a)

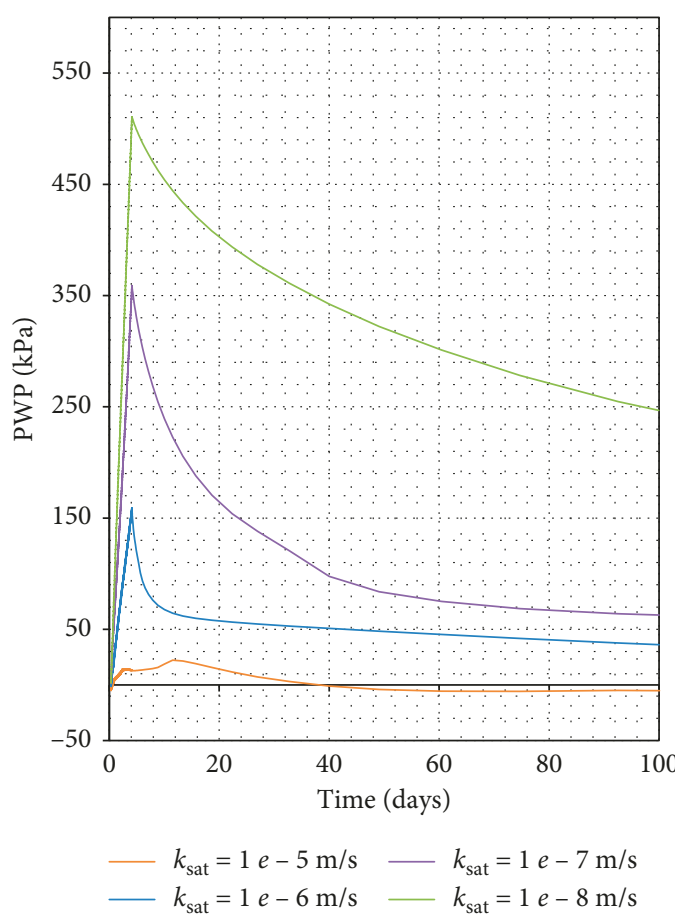

(b)

Figure 10: Evolution of the (a) horizontal total stress $\sigma_{\mathrm{h}}$ and (b) PWP $u_{\mathrm{w}}$ at midheight of the barricade for four different hydraulic conductivities of backfill (see the details in Table 1, Case 2).

3.1.5. Filling Rate $V$. Figure 13 shows the variation of the horizontal total stress $\sigma_{\mathrm{h}}$ (Figure 13(a)) and PWP $u_{\mathrm{w}}$ (Figure 13(b)) at midheight of the drift on the barricade, after the start of stope filling for filling rate $V$ of $0.1,0.2,0.3$, 0.4 , and $1 \mathrm{~m} / \mathrm{h}$. When the stope filling rate is $1 \mathrm{~m} / \mathrm{h}$, the horizontal total stress and PWP reach a peak value shortly 


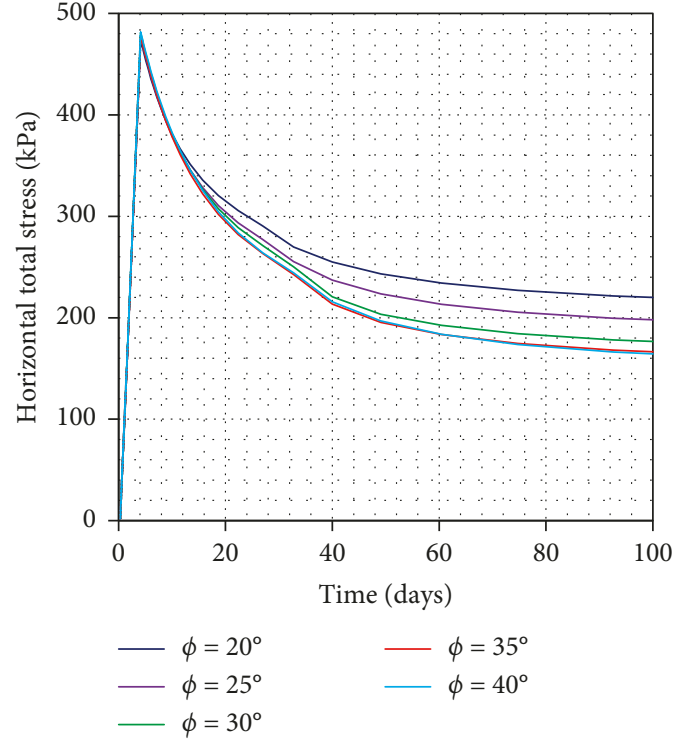

(a)

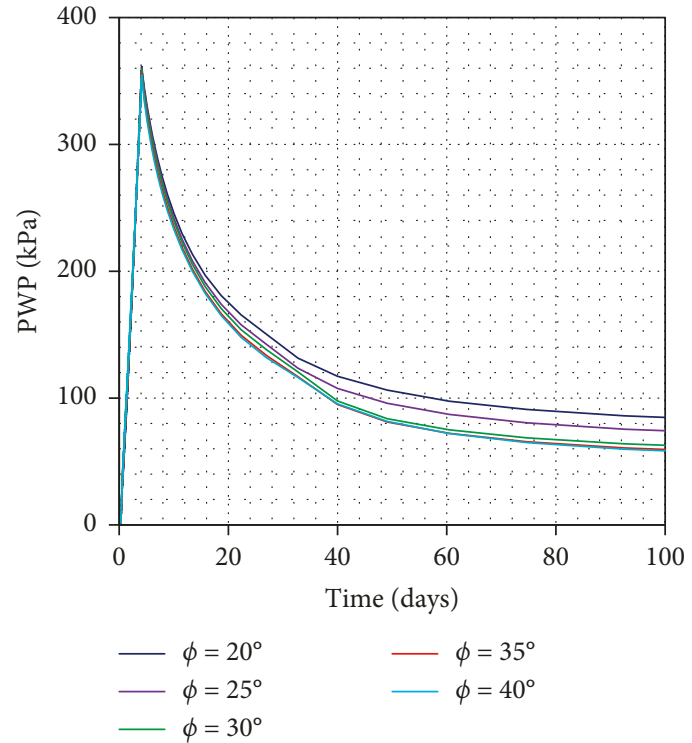

(b)

Figure 11: Evolution of the (a) horizontal total stress $\sigma_{\mathrm{h}}$ and (b) PWP $u_{\mathrm{w}}$ at midheight of the barricade for five different values of the backfill frictional angle (see the details in Table 1, Case 5).

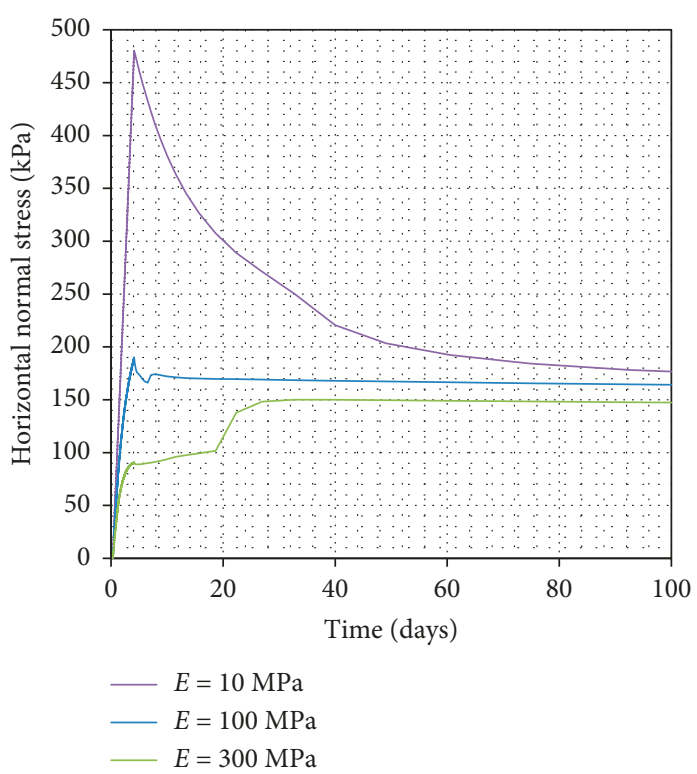

(a)

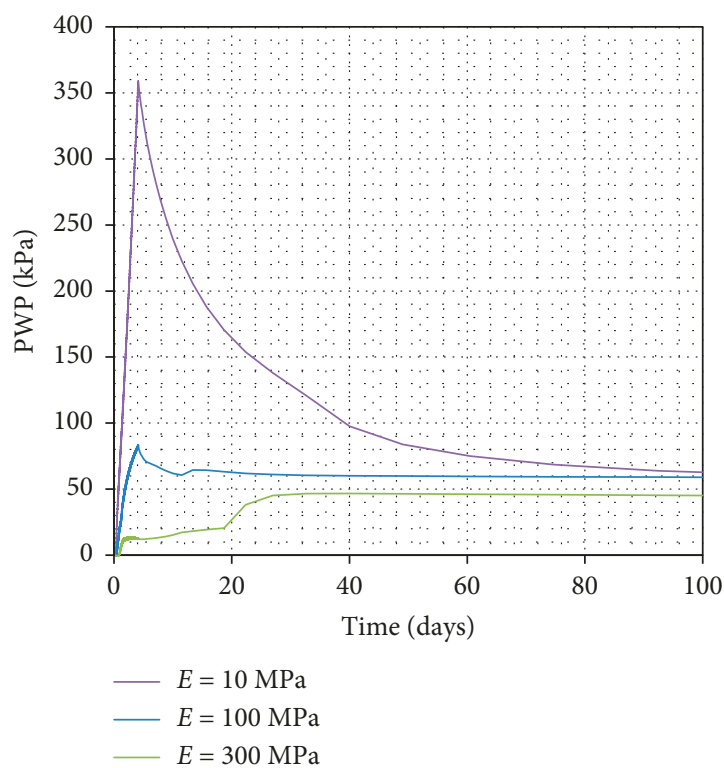

(b)

Figure 12: Evolution of the (a) horizontal total stress $\sigma_{\mathrm{h}}$ and (b) PWP $u_{\mathrm{w}}$ at midheight of the barricade for three different values of the backfill modulus (see the details in Table 1, Case 7).

(i.e., 1.25 days) after the completion of the stope filling, with maximum values of $\sigma_{\mathrm{h}}=530 \mathrm{kPa}$ and $u_{\mathrm{w}}=450 \mathrm{kPa}$. When the filling rate decreases, the peak values in the horizontal total stress and PWP are reached later, and the peak values tend to diminish. The peak values are $\sigma_{\mathrm{h}}=489 \mathrm{kPa}$ and $u_{\mathrm{w}}=380 \mathrm{kPa}$ for a filling rate of $0.4 \mathrm{~m} / \mathrm{h}, \sigma_{\mathrm{h}}=476 \mathrm{kPa}$ and $u_{\mathrm{w}}=357 \mathrm{kPa}$ for a filling rate of $0.3 \mathrm{~m} / \mathrm{h}, \sigma_{\mathrm{h}}=441 \mathrm{kPa}$ and $u_{\mathrm{w}}=322 \mathrm{kPa}$ for a filling rate of $0.2 \mathrm{~m} / \mathrm{h}$, and $\sigma_{\mathrm{h}}=391 \mathrm{kPa}$ and $u_{\mathrm{w}}=256 \mathrm{kPa}$ for a filling rate of $0.1 \mathrm{~m} / \mathrm{h}$. These results indicate that higher peak stresses and PWPs should be expected with faster filling. These results are in agreement with those of El Mkadmi et al. [39].

3.1.6. Number of Draining Holes $n_{d}$. Figure 14 shows the evolution of the horizontal total stress $\sigma_{\mathrm{h}}$ (Figure 14(a)) and PWP $u_{\mathrm{w}}$ (Figure 14(b)) at midheight of the drift on the barricade, after the start of stope filling for 0 to 5 draining 


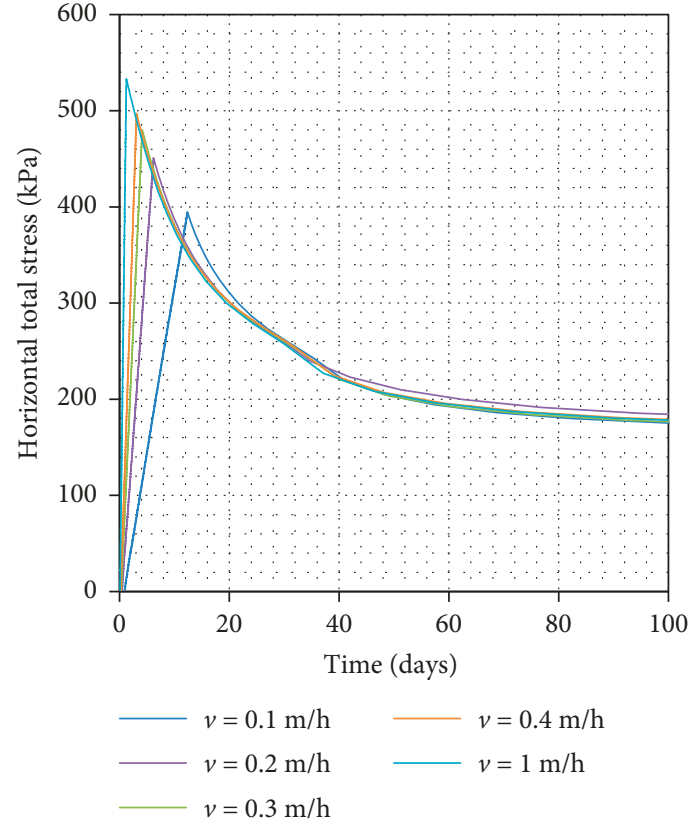

(a)

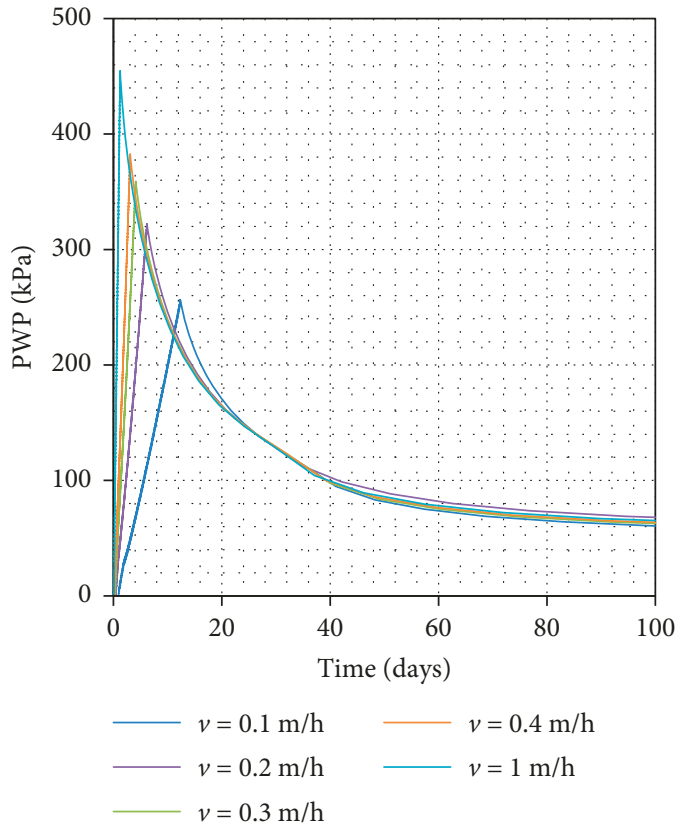

(b)

Figure 13: Evolution of the (a) horizontal total stress $\sigma_{\mathrm{h}}$ and (b) PWP $u_{\mathrm{w}}$ at midheight of the barricade for five different values of filling rate (see the details in Table 1, Case 3).

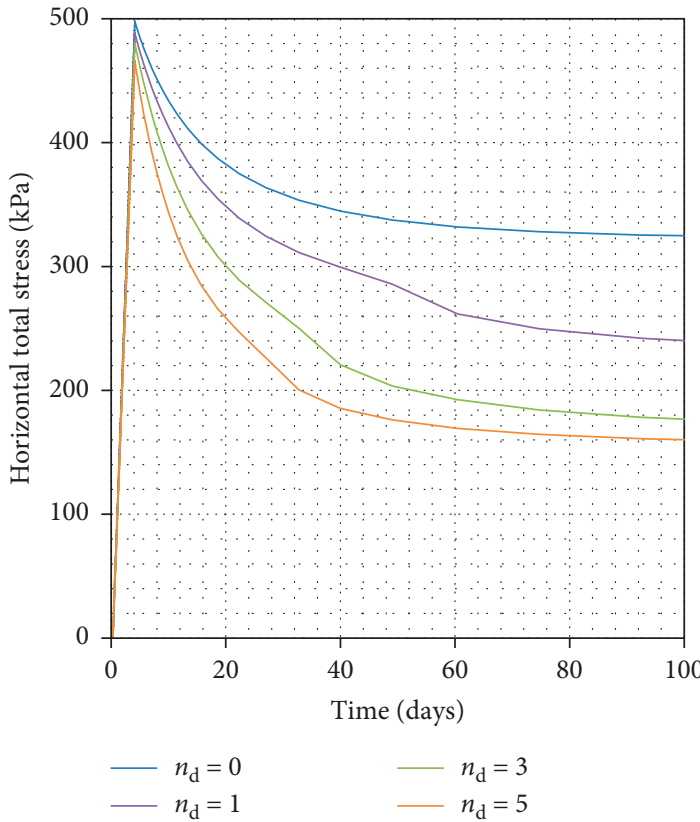

(a)

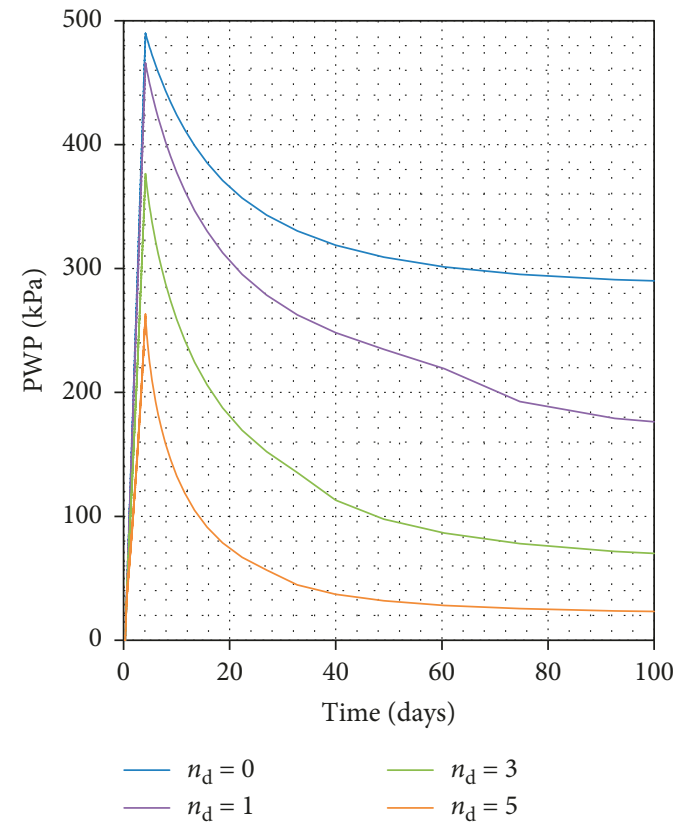

(b)

Figure 14: Evolution of the (a) horizontal total stress $\sigma_{\mathrm{h}}$ and (b) PWP $u_{\mathrm{w}}$ at midheight of the barricade for four different numbers of draining holes through the barricade (see the details in Table 1, Case 4).

holes through the barricade. One sees that the number of draining holes can significantly affect the peak values of the PWP (Figure 14(b)), but the peak values of the horizontal total stress do not change significantly with the number of draining holes (Figure 14(a)). Without draining hole $\left(n_{\mathrm{d}}=0\right)$, the peak value of horizontal total stress reaches $\sigma_{\mathrm{h}}=497 \mathrm{kPa}$ and the peak PWP $u_{\mathrm{w}}=488 \mathrm{kPa}$. With 5 draining holes $\left(n_{\mathrm{d}}=5\right)$, the peak value of horizontal total stress $\sigma_{\mathrm{h}}$ is $465 \mathrm{kPa}$, but the peak value of PWP is significantly reduced to $262 \mathrm{kPa}$. Once the stope filling operation is completed, the horizontal stress and PWP on the barricade tend to decrease. At a time of 32 days after the start of filling, 
the horizontal total stress and PWP are $\sigma_{\mathrm{h}}=354 \mathrm{kPa}$ and $u_{\mathrm{w}}=320 \mathrm{kPa}$ for $n_{\mathrm{d}}=0, \sigma_{\mathrm{h}}=311 \mathrm{kPa}$ and $u_{\mathrm{w}}=249 \mathrm{kPa}$ for $n_{\mathrm{d}}=1, \quad \sigma_{\mathrm{h}}=250 \mathrm{kPa}$ and $u_{\mathrm{w}}=120 \mathrm{kPa}$ for $n_{\mathrm{d}}=3$, and $\sigma_{\mathrm{h}}=201 \mathrm{kPa}$, and $u_{\mathrm{w}}=41 \mathrm{kPa}$ for $n_{\mathrm{d}}=5$. The horizontal total stress and PWP tend to stabilize in the long term at $\sigma_{\mathrm{h}}=322 \mathrm{kPa}$ and $u_{\mathrm{w}}=285 \mathrm{kPa}$ without draining hole and $\sigma_{\mathrm{h}}=130 \mathrm{kPa}$ and $u_{\mathrm{w}}=13 \mathrm{kPa}$ with 5 draining holes.

Draining holes are commonly used to reduce the PWP and improve the stability of retaining structures. The results presented here confirm that the addition of draining holes can help to reduce the peak value of the PWP, but this has a limited effect on the peak value of the total stresses (and total load) exerted by the backfill on the barricade. The addition of draining holes can help improve the long-term stability of this retaining structure, but it has little impact on the "shortterm" stability (shortly after the completeness of the stope filling) of the barricade.

3.1.7. Position of the Barricade $L_{d}$. Figure 15 shows the evolution of the horizontal total stress $\sigma_{\mathrm{h}}$ (Figure 15(a)) and PWP $u_{\mathrm{w}}$ (Figure 15(b)) at midheight of the drift on the barricade, from the start of stope filling when the barricade is positioned in the drift at a distance $L_{\mathrm{d}}$ of $0.25,0.5,1.5,3$, and $6 \mathrm{~m}$ from the stope entrance. Figure 14(a) indicates that the peak value of the horizontal total stress exerted on the barricade does not change significantly with the position of $L_{\mathrm{d}}$. These results are due to the very small arching effect that develops in the short term. Figure 15(b) indicates that the peak values of the PWP tend to increase when the barricade is farther from the stope entrance for $L_{\mathrm{d}} \leq 0.5 \mathrm{~m}$; beyond this value $L_{\mathrm{d}}$, the peak value tends to diminish when the barricade is positioned farther from the stope entrance. The horizontal total stress does not change significantly with the position of the barricade. For the material properties given, the stability of the barricade is not sensitive to the position.

\section{Discussion}

Numerical modeling can be a useful tool to analyse the hydrogeotechnical behavior of backfilled openings. However, one should keep in mind that the numerical modeling conducted in this study contains several limitations. For example, the numerical models are two dimensional (plane strain). The effect of the third dimension of the drift and barricade has been considered indirectly for the hydraulic (water flow) aspect, but neglected for the mechanical aspects (stress state). As this problem is truly three dimensional, it should be treated using 3D numerical models.

In this study, the top surface of the backfill is simulated as impervious to reproduce ponding on top of the backfill, a phenomenon commonly observed in practice [53-55]. The ponding is reflected by the positive PWP and total stresses on the top surface of the backfill, as shown in Figure 5. Alternatively, fictive reservoir elements above the top surface of the backfill can be used to simulate the accumulation of water above the top surface of the backfill $[55,56]$.

Figure 16 shows the evolution of the PWP and vertical total stress on top surface of the backfill, obtained by the numerical modeling with and without (this study) fictive reservoir elements above the top surface of the backfill. Almost identical results are obtained by the numerical modeling with the two different hydraulic boundary conditions imposed along the top surface of the backfill for the period considered, with a small but non-negligible effective stress in both cases. These results, however, implicitly assume that the top surface of the backfill is the top surface of the settled backfill. In the reality, the top surface (or water level) of the slurried backfill should remain constant if there is neither evaporation nor water drainage through the barricade. The surface of the settled backfill goes down with the drainage and consolidation of the backfill. If the top surface of the numerical model is considered as the top surface (or water level) of the slurried backfill, the numerical results on the top surface of the backfill presented in Figures 5 and 16 might be considered as unrealistic because the PWP and total stresses should remain nil along the top (water) surface of the slurried backfill. Numerical modeling has also be done by imposing seepage free or zero head hydraulic boundary condition along the top surface of the backfill. Zero PWP and zero total stresses along the top surface of the backfill can be obtained, but the ponding phenomenon cannot be reproduced. More work is needed to reproduce the ponding phenomenon and keep zero PWP and zero total stresses on top of the backfill. A numerical model allowing large strain consolidation is necessary.

In this study, the rock walls were considered as impermeable here. In practice, the rock mass includes joints, fractures, and other geological structures. Water flow can take place through these geological structures (e.g., [57]) and affect the drainage and consolidation of the backfill. Neglecting this aspect would typically lead to conservative design of barricade, but more work is necessary to better understand the effect of the geological structures on the PWP and total stresses in the stope and on the barricade.

The Mohr-Coulomb elastoplastic model has been used here (and in many other investigations). However, the Mohr-Coulomb criterion may not represent well the geomechanical behavior of the backfill, particularly at low to negative mean stresses. More elaborated and representative models are available and are sometime used to investigate the behavior of backfilled stopes (e.g., [34]).

Another limitation of the numerical simulations conducted here is associated with the neglect of the evolution of the backfill properties due to the cement hydration. This was assessed partly by El Mkadmi et al. [39]. As the peak values of the PWP and total stresses occur during the filling operation, the most critical moment for the stability analysis and design of the barricades is during the stope filling. The drainage and consolidation processes are important to be considered. However, when the stopes are large and the filling time is long, the cementation of cemented backfill may significantly reduce the pressure and stresses in the stopes and on the barricades. Neglecting the effect of cementation can lead to overly conservative design of barricades. More work is necessary to properly take into account the effect of cementation on the barricade design. 


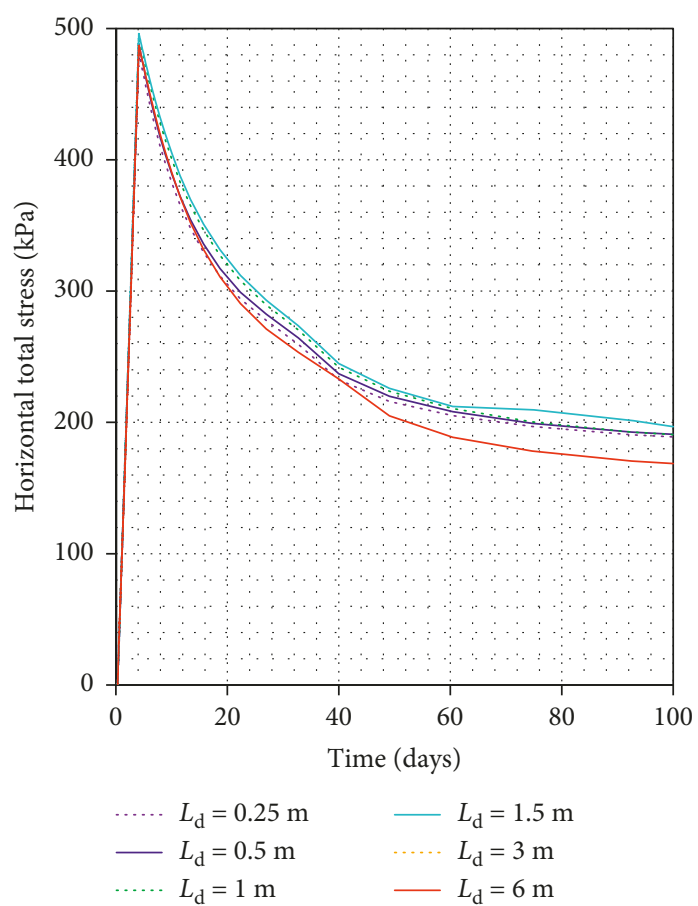

(a)

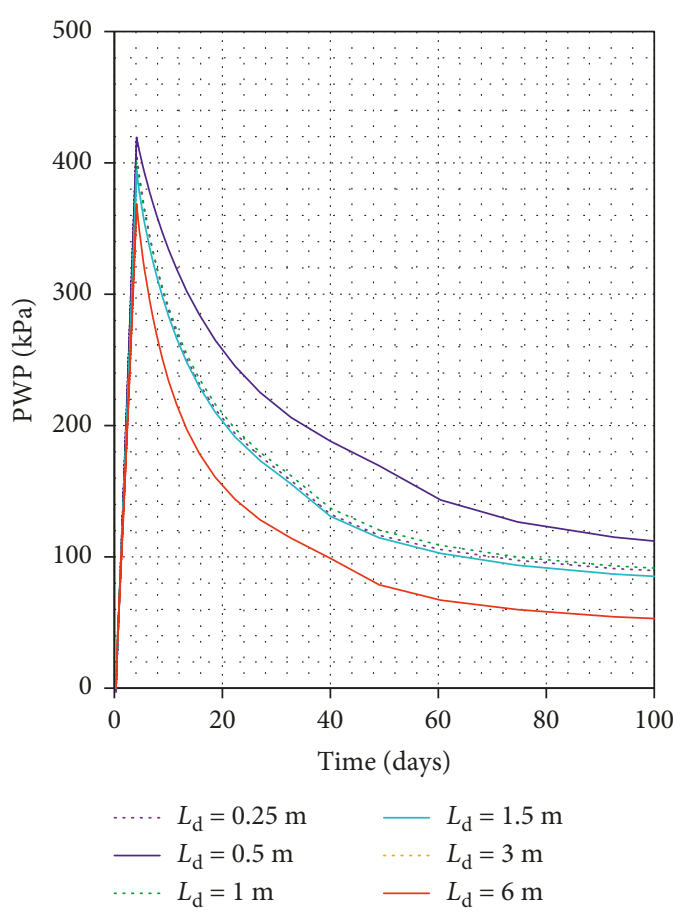

(b)

FIgURE 15: Evolution of the (a) horizontal total stress $\sigma_{\mathrm{h}}$ and (b) PWP $u_{\mathrm{w}}$ at midheight of the barricade, from the start of stope filling when the barricade is positioned in the drift at different distances from the stope entrance (see the details in Table 1, Case 6).

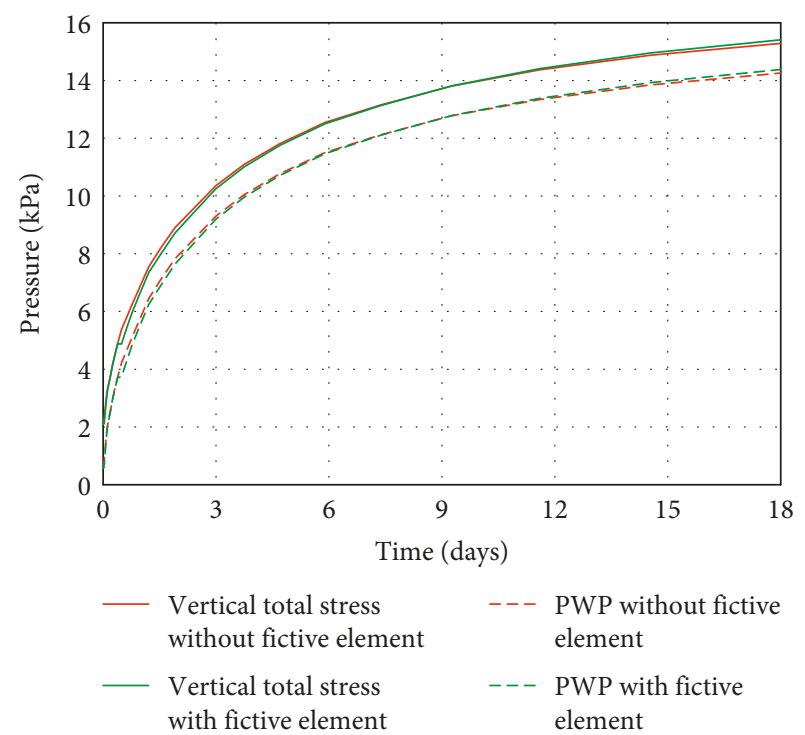

Figure 16: Evolution of the PWP and vertical total stress on top surface of the backfill, obtained by the numerical modeling with and without (this study) fictive elements above the top surface of the backfill.

This study focused on a barricade typically made of shotcrete or other impervious materials. In practice, barricades can be made of several materials, such as wood, brick, concrete blocks, waste rocks, and so on. In Canada and Australia, construction of barricades made of pervious waste rock has become more and more popular (e.g., $[58,59])$.
Work is ongoing to investigate the mechanical behavior of backfill placed in backfilled stope with waste rock barricades.

Finally, it should be noted that the numerical models need to be validated (or calibrated) by experimental results obtained from laboratory or field measurements.

\section{Conclusions}

In this paper, a number of numerical simulations have been performed to assess the influence of the stope geometry and backfill properties on the total stresses and PWPs in the backfilled stopes and on the barricades. Emphasis was given on the pressure and stresses on the barricades, mainly for the design of barricade. The effect of drift size, barricade location, and number of draining holes is for the first time investigated.

The results indicate that an increase in the stope width may result in higher PWPs and horizontal total stresses on the barricade. Higher peak stresses and PWPs can also be expected with faster filling rate. It is particularly interesting to note that the addition of draining holes can be helpful to reduce the PWP but this has little effect on the total stresses and loads on the barricade in the short term. Both the total stress and PWP are significantly reduced by the addition of draining holes in the long term.

The position of the barricade can also change the peak values of the PWP, but this has only a limited influence on the peak values of the total stress exerted on the barricade.

The frictional angle of the backfill has a limited influence on the stresses and pressures on the barricade in the shortterm. The hydraulic conductivity of the backfill influences 
much more significantly the total stresses and PWPs. Simulations indicate that the peak total stresses and PWPs tend to increase as the saturated hydraulic conductivity decreases. The application of paste fill can result in significantly higher peak PWPs and total stresses than hydraulic backfill.

The results also indicate that the long-term stiffness of the backfill can significantly affect the stresses and pressures exerted by the backfill on the barricade. A stiffer backfill leads to lower loads on the barricade. It is thus advantageous to increase the stiffness of the backfill.

\section{Appendix}

\section{Validation of SIGMA/W for Consolidation Analysis}

Figure 17 shows a cylindrical clay sample $3.5 \mathrm{~cm}$ high with $4 \mathrm{~cm}$ in diameter, submitted to standard consolidation test conditions $[42,60]$. The top surface is permeable and subjected to an instantaneous surcharge pressure $\sigma_{\mathrm{v}}=392 \mathrm{kPa}$. The clay is characterized by $e_{0}=1$ (initial void ratio), $\gamma=20 \mathrm{kN} / \mathrm{m}^{3}$ (unit weight), $E=1779 \mathrm{kPa}$ (Young modulus), $\mu=0.33$ (Poisson' ratio), $c=0 \mathrm{kPa}$ (cohesion), $\phi=30^{\circ}$ (friction angle), and $k_{\text {sat }}=10^{-9} \mathrm{~m} / \mathrm{s}$ (saturated hydraulic conductivity). These parameters were used by Helwany [60] to validate the numerical code ABAQUS.

Terzaghi [61] has proposed the following equation to evaluate the excess PWP $u^{\prime}$ [62]:

$$
u^{\prime}=\sigma_{\mathrm{v}} \sum_{m=0}^{m=\infty} \frac{2}{M} \sin \left(M \frac{z}{H_{\mathrm{dr}}}\right) \exp \left(-M^{2} T_{\mathrm{v}}\right),
$$

while the degree of drainage and consolidation $U$, defined as the ratio between the dissipation of excess PWP and the initial excess PWP, can be assessed by the following equation [62]:

$$
U=1-\sum_{m=0}^{m=\infty} \frac{2}{M^{2}} \exp \left(-M^{2} T_{v}\right),
$$

where $H_{\mathrm{dr}}$ is the maximum distance of drainage path $(m) ; z$ is the depth $\left(0 \leq z \leq H_{\mathrm{dr}}\right) ; M=(2 m+1) \pi / 2, m=0,1,2,3, \ldots$, $\infty$; and $T_{\mathrm{v}}$ is time factor (-), defined as follows [61]:

$$
T_{\mathrm{v}}=\frac{c_{\mathrm{v}} t}{H_{\mathrm{dr}}^{2}},
$$

where $c_{\mathrm{v}}$ is the coefficient of consolidation $\left(\mathrm{m}^{2} / \mathrm{s}\right)$, which can be estimated by the following equation:

$$
c_{\mathrm{v}}=\frac{1}{\gamma_{\mathrm{w}}} \frac{k_{\mathrm{sat}}}{m_{\mathrm{v}}}
$$

where $k_{\text {sat }}$ is the saturated hydraulic conductivity $(\mathrm{m} / \mathrm{s})$ and $m_{\mathrm{v}}$ is the coefficient of volume compressibility, expressed as follows:

$$
m_{\mathrm{v}}=\frac{1}{E} \frac{(1+\mu)(1-2 \mu)}{(1-\mu)} .
$$

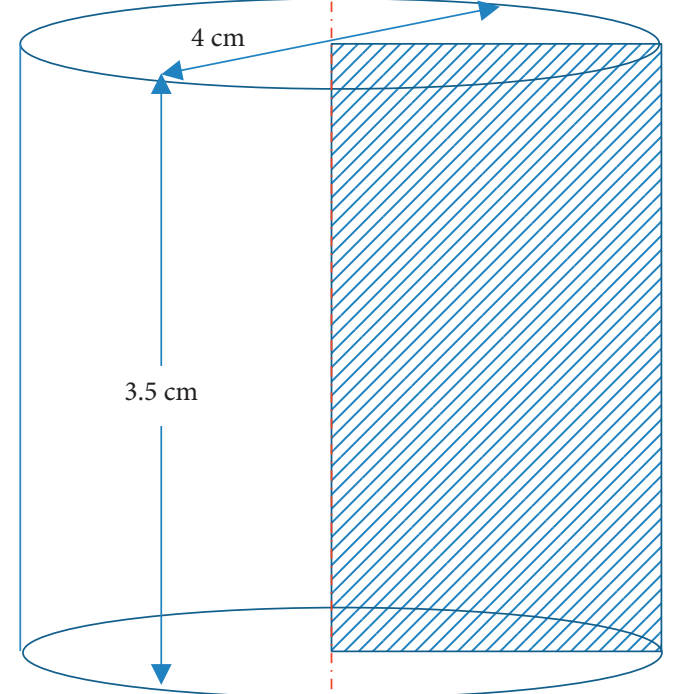

FIGURE 17: A clay cylinder submitted to the standard consolidation test condition.

With $\gamma_{\mathrm{w}}=10 \mathrm{kN} / \mathrm{m}^{3}, \quad E=1779 \mathrm{kPa}, \quad \mu=0.33, \quad$ and $k_{\text {sat }}=10^{-9} \mathrm{~m} / \mathrm{s}$, one obtains $c_{\mathrm{v}}=2.69 \times 10^{-7} \mathrm{~m}^{2} / \mathrm{s}$. Introducing this value and $\mathrm{H}_{\mathrm{dr}}=0.035 \mathrm{~m}$ in equation (A.3) leads to the time factor $T_{\mathrm{v}}$ as follows:

$$
T_{\mathrm{v}}=2.2 \times 10^{-4} t .
$$

The evolution of the excess PWP and degree of drainage and consolidation can then be calculated with equations (A.1), (A.2), and (A.6) while the vertical effective stress $\sigma_{\mathrm{v}}^{\prime}$ can be obtained as follows:

$$
\sigma_{\mathrm{v}}^{\prime}=\sigma_{\mathrm{v}}-\left(u^{\prime}+\gamma_{\mathrm{w}} z\right),
$$

where $\gamma_{\mathrm{w}}$ is the unit weight of water $\left(\mathrm{kN} / \mathrm{m}^{3}\right)$.

Figure 18(a) shows a numerical model of the consolidation test shown in Figure 17, built with SIGMA/W. The axis-symmetry is taken into account in the numerical model. The clay is considered as elastoplastic, obeying the MohrCoulomb criterion. The two impermeable side boundaries are fixed in horizontal direction and free in vertical direction. The impermeable base boundary is fixed both in horizontal and vertical directions. The top boundary is submitted to a loading function, as shown in Figure 18(b). Drainage is allowed with a zero PWP along the top surface of the sample.

Figure 19 shows the evolution of the PWP, vertical effective stress, and degree of consolidation at the base center (Point A, Figure 18(a)) of the sample, calculated by the analytical solution of Terzaghi [61] and estimated by the numerical modeling with SIGMA/W. Differences can be observed between the numerical and analytical results. In the model of [61], the excess PWP associated with the surcharge on top of the sample is assumed to be fully and instantaneously generated. The excess PWP dissipation process starts at time $t=0$. In the numerical model, a surcharge can be applied very quickly on the top of the sample (Figure 18(b)), but time is needed to generate the full excess PWP through the whole sample. The excess PWP dissipation 


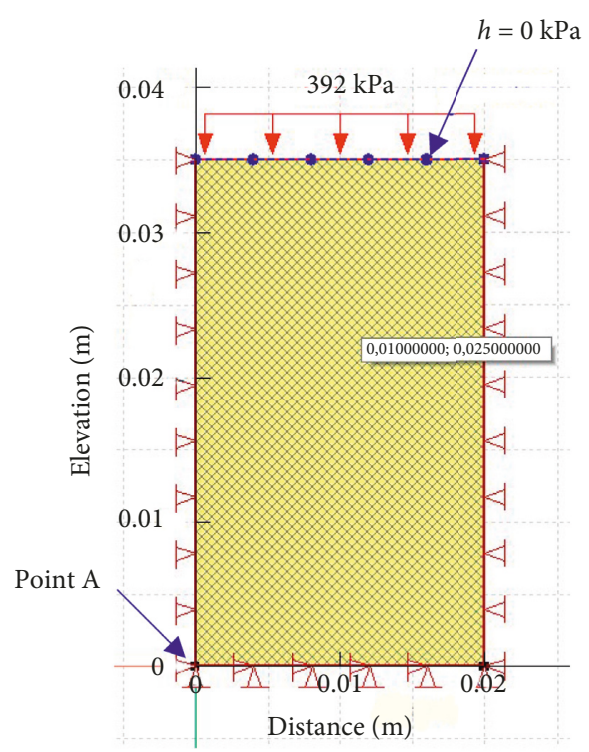

(a)

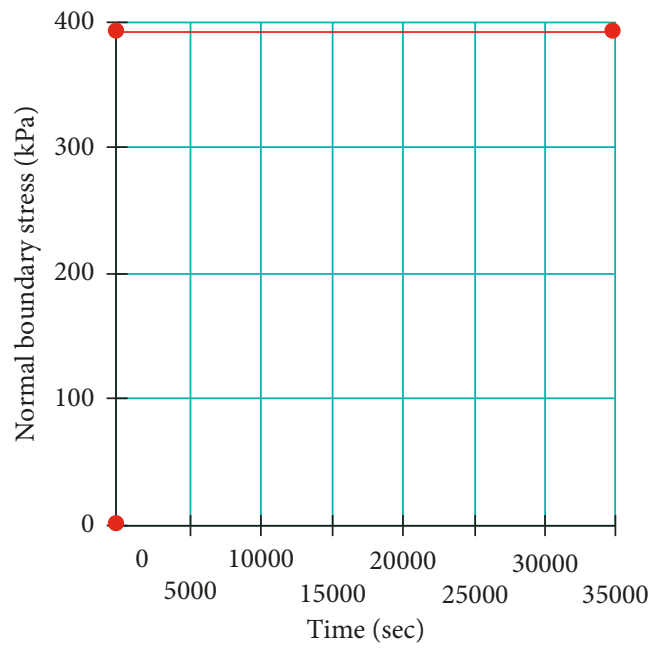

(b)

FIGURE 18: (a) The numerical model of the clay cylinder, built with SIGMA/W after considering the axis-symmetry; (b) loading function applied in the numerical model.

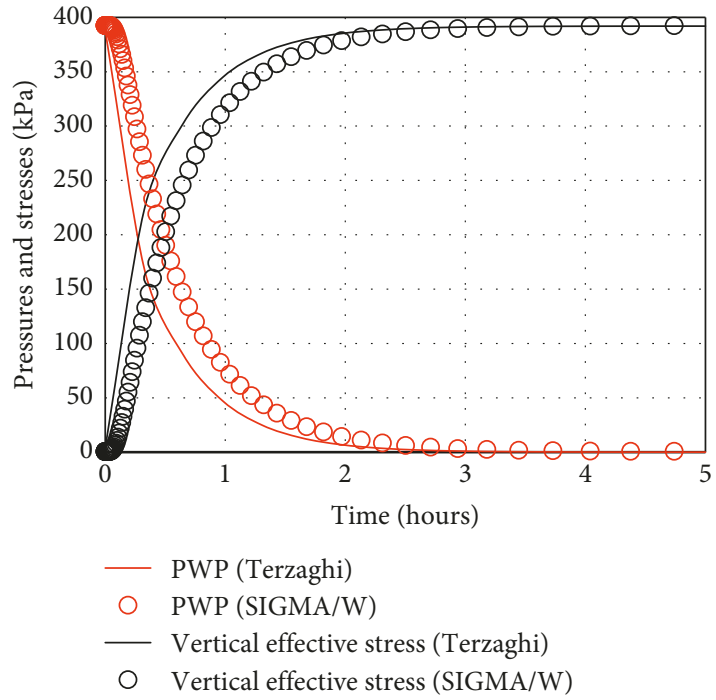

(a)

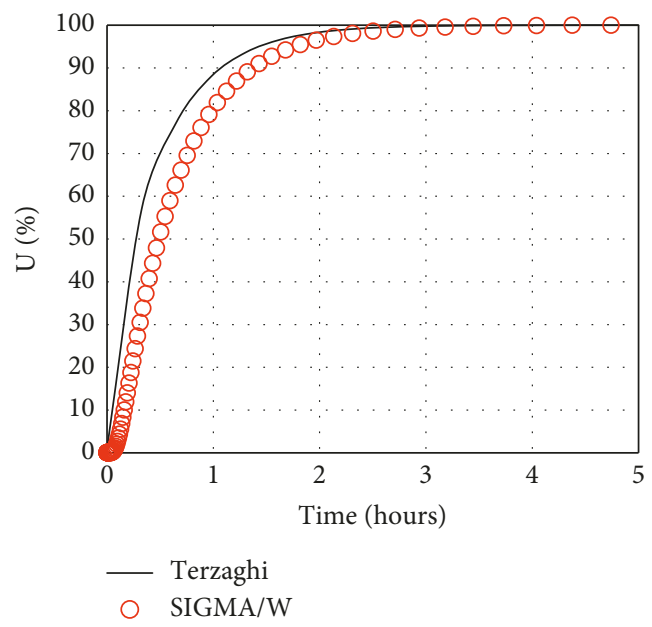

(b)

FIGURE 19: Degrees of consolidation, calculated by the analytical solution (equation (A.1)) and estimated by the numerical modeling with SIGMA/W.

process starts at time $t>0$ (about 0.055 hours) after the application of the top load. Subsequently, one sees some delay in the dissipation of the excess PWP in the numerical results, compared to the analytical solution. Nevertheless, the quite good agreement between the analytical and numerical results shown in Figure 19 indicates that SIGMA/W is a useful tool to analyse the drainage and consolidation of soils and backfills.

\section{Data Availability}

No data were used to support this study.

\section{Conflicts of Interest}

The authors declare that there are no conflicts of interest regarding the publication of this paper.

\section{Acknowledgments}

The authors would like to acknowledge the financial support from the Natural Sciences and Engineering Research Council of Canada (NSERC 402318), Institut de Recherche Robert-Sauvé en Santé et en Sécurité du Travail (IRSST 20130029), Fonds de recherche du Québec-Nature et 
Technologies (2015-MI-191676), and industrial partners of the Research Institute on Mines and the Environment (RIME UQAT-Polytechnique; http://rime-irme.ca/).

\section{References}

[1] M. Aubertin, B. Bussière, and L. Bernier, Environnement et Gestion des Rejets Miniers, Presses Internationales de Polytechnique, Montreal, Quebec, Canada, 2002.

[2] M. Benzaazoua, B. Bussière, I. Demers, M. Aubertin, É. Fried, and A. Blier, "Integrated mine tailings management by combining environmental desulphurization and cemented paste backfill: application to mine Doyon, Quebec, Canada," Minerals Engineering, vol. 21, no. 4, pp. 330-340, 2008.

[3] C. Qi, Q. Chen, A. Fourie et al., "Constitutive modelling of cemented paste backfill: a data-mining approach," Construction and Building Materials, vol. 197, pp. 262-270, 2019.

[4] C. Qi, A. Fourie, Q. Chen, and P. Liu, "Application of firstprinciples theory in ferrite phases of cemented paste backfill," Minerals Engineering, vol. 133, pp. 47-51, 2019.

[5] C. Qi, X. Tang, X. Dong, Q. Chen, A. Fourie, and E. Liu, "Towards intelligent mining for backfill: a genetic programming-based method for strength forecasting of cemented paste backfill," Minerals Engineering, vol. 133, pp. 69-79, 2019.

[6] P. Darling, SME Mining Engineering Handbook, SME, Bratislava, Slovakia, Third edition, 2011.

[7] B. D. Thompson, W. F. Bawden, and M. W. Grabinsky, "In situ measurements of cemented paste backfill at the cayeli mine," Canadian Geotechnical Journal, vol. 49, no. 7, pp. 755-772, 2012.

[8] T. Grice, "Stability of hydraulic backfill barricades," in Proceedings of the 6th International Symposium on Mining with Backfill (MineFill'98), M. Bloss, Ed., pp. 117-120, AusIMM, Brisbane, Australia, April 1998.

[9] M. Helinski and A. G. Grice, "Water management in hydraulic fill operations," in Proceedings of the 9th International Symposium on Mining with Backfill (Minefill'07), CIM, Montreal, Quebec, Canada, May 2007.

[10] M. B. Revell and D. P. Sainsbury, "Advancing paste fill bulkhead design using numerical modeling," in Proceedings of the 9th International Symposium on Mining with Backfill (Minefill'07), Montreal, Quebec, Canada, April 2007.

[11] M. Yumlu and M. Guresci, "Paste backfill bulkhead monitoring - a case study from inmet's cayeli mine, Turkey," in Proceedings of the 9th International Symposium on Mining with Backfill (Minefill'07), CIM, Montreal, Quebec, Canada, May 2007.

[12] N. Sivakugan and S. Widisinghe, "Stresses within granular materials contained between vertical walls," Indian Geotechnical Journal, vol. 43, no. 1, pp. 30-38, 2013.

[13] C. Lee, "Paste backfill system implementation from concept design through to operation," in Proceedings of the Symposium Rouyn-Noranda sur L'environnement et les Mines, CIM, Rouyn-Noranda, Quebec, Canada, June 2015.

[14] M. Fahey, M. Helinski, and A. Fourie, "Consolidation in accreting sediments: gibson's solution applied to backfilling of mine stopes," Géotechnique, vol. 60, no. 11, pp. 877-882, 2010.

[15] R. E. Gibson, "The progress of consolidation in a clay layer increasing in thickness with time," Géotechnique, vol. 8, no. 4, pp. 171-182, 1958.

[16] L. Li, I. C. Alvarez, and J. D. Aubertin, "Self-weight consolidation of slurried deposition: tests and interpretation,"
International Journal of Geotechnical Engineering, vol. 7, no. 2, pp. 205-213, 2013.

[17] L. Pedroni, Étude expérimentale et numérique de la sédimentation et de la consolidation des boues de traitement des eaux acides, Ph.D. dissertation, École Polytechnique de Montréal, Montreal, Canada, 2011.

[18] J. Zheng, L. Li, M. Mbonimpa, and T. Pabst, "An analytical solution of gibson's model for estimating the pore water pressures in accreting deposition of slurried material under one-dimensional self-weight consolidation. part I: pervious base," Indian Geotechnical Journal, vol. 48, no. 1, pp. 72-83, 2018.

[19] J. P. Doherty and D. Muir Wood, "Back analysis of the Kanowna Belle stope filling case history," Computers and Geotechnics, vol. 76, pp. 201-211, 2016.

[20] J. E. Askew, P. L. McCarthy, and D. J. Fitzerald, "Backfill research for pillar extraction at $\mathrm{ZC} / \mathrm{NBHC}$," International Journal of Rock Mechanics and Mining Sciences \& Geomechanics Abstracts, vol. 17, no. 2, p. 30, 1980.

[21] A. Jahanbakhshzadeh, M. Aubertin, and L. Li, "Threedimensional stress state in inclined backfilled stopes obtained from numerical simulations and new closed-form solution," Canadian Geotechnical Journal, vol. 55, no. 6, pp. 810-828, 2018.

[22] E. M. Jaouhar, L. Li, and M. Aubertin, "An analytical solution for estimating the stresses in vertical backfilled stopes based on a circular arc distribution," Geomechanics and Engineering, vol. 15, no. 3, pp. 889-898, 2018.

[23] L. Li and M. Aubertin, "A three-dimensional analysis of the total and effective stresses in submerged backfilled stopes," Geotechnical and Geological Engineering, vol. 27, no. 4, pp. 559-569, 2009a.

[24] L. Li and M. Aubertin, "An analytical solution for the nonlinear distribution of effective and total stresses in vertical backfilled stopes," Geomechanics and Geoengineering, vol. 5, no. 4, pp. 237-245, 2010.

[25] K. Pirapakaran and N. Sivakugan, "Arching within hydraulic fill stopes," Geotechnical and Geological Engineering, vol. 25, no. 1, pp. 25-35, 2007.

[26] C. H. Ting, S. K. Shukla, and N. Sivakugan, "Arching in soils applied to inclined mine stopes," International Journal of Geomechanics, vol. 11, no. 1, pp. 29-35, 2011.

[27] L. D. Suits, T. C. Sheahan, C. H. Ting, N. Sivakugan, and S. K. Shukla, "Laboratory simulation of the stresses within inclined stopes," Geotechnical Testing Journal, vol. 35, no. 2, pp. 280-294, 2012.

[28] B. Yan, W. Zhu, C. Hou, and K. Guan, "A three-dimensional analytical solution to the arching effect in inclined backfilled stopes," Geomechanics and Geoengineering, vol. 14, no. 2, pp. 136-147, 2019.

[29] T. Belem, A. Harvey, R. Simon, and M. Aubertin, "Measurement of internal pressures of a gold mine pastefill during and after the stope backfilling," in Proceedings 5th International Symposium Ground Support in Mining and Underground Construction, Perth, Western Australia, September 2004.

[30] S. Knutsson, "Stresses in the hydraulic backfill from analytical calculations and in situ measurements," in Proceedings of Conference on Application of Rock Mechanical to Cut and Fill Mining, Institution of Mining and Metallurgy, pp. 261-268, London, UK, October 1981.

[31] K. Pirapakaran and N. Sivakugan, "A laboratory model to study arching within a hydraulic fill stope," Geotechnical Testing Journal, vol. 30, no. 6, article 100653, 2007. 
[32] N. Falaknaz, M. Aubertin, and L. Li, "Numerical investigation of the geomechanical response of adjacent backfilled stopes," Canadian Geotechnical Journal, vol. 52, no. 10, pp. 1507-1525, 2015.

[33] L. Li and M. Aubertin, "Numerical investigation of the stress state in inclined backfilled stopes," International Journal of Geomechanics, vol. 9, no. 2, pp. 52-62, 2009.

[34] L. Li, M. Aubertin, and A. Shirazi, "Implementation and application of a new elastoplastic model based on a multiaxial criterion to assess the stress state near underground openings," International Journal of Geomechanics, vol. 10, no. 1, pp. 13-21, 2010.

[35] C. R. Newman, Numerical analysis of stress distributions for multiple backfilled stopes, Ph.D. dissertation, University of Kentucky, Lexington, KY, USA, 2018.

[36] L. Li and M. Aubertin, "Horizontal pressure on barricades for backfilled stopes. part II: submerged conditions," Canadian Geotechnical Journal, vol. 46, no. 1, pp. 47-56, 2009.

[37] M. Shahsavari and M. Grabinsky, "Mine backfill pore water pressure dissipation: numerical predictions and field measurements," in Proceedings of the 68th Canadian Geotechnical Conference, CGS, Quebec City, Canada, September 2015.

[38] J. Zheng, L. Li, and Y. Li, "Total and effective stresses in backfilled stopes during the fill placement on a pervious base for barricade design," Minerals, vol. 9, no. 1, p. 38, 2019.

[39] N. El Mkadmi, M. Aubertin, and L. Li, "Effect of drainage and sequential filling on the behavior of backfill in mine stopes," Canadian Geotechnical Journal, vol. 51, no. 1, pp. 1-15, 2014.

[40] Geo-Slope, Stress-Deformation Modeling with SIGMA/W 2007, GEO-SLOPE International Ltd., 3rd edition, 2007.

[41] N. El Mkadmi, "Simulations du comportement géotechnique des remblais dans les chantiers miniers: effets du drainage et de la consolidation," Master thesis, École Polytechnique de Montréal, Montréal, Canada, 2012.

[42] E. M. Jaouhar, Développement de solutions analytiques et numériques pour évaluer la distribution des contraintes dans les chantiers miniers remblayés et sur les barricades, Ph.D. thesis, Ecole Polytechnique de Montréal, Montréal, Canada, 2019, in French.

[43] M. A. Sobhi, "Analyse numérique du coefficient de pression latérale des terres et des contraintes dans les chantiers miniers," Master's thesis, Ecole Polytechnique de Montreal, Montréal, Canada, 2014.

[44] J. M. Duncan and A. Bursey, "Soil modulus correlations," in Proceedings of the Foundation Engineering in the Face of Uncertainty: Honoring Fred H. Kulhawy, pp. 321-336, ASCE, San Diego, CA, USA, March 2013.

[45] A. Jahanbakhshzadeh, Analyse $d u$ comportement géomécanique des remblais miniers dans des excavations souterraines inclinées, Ph.D. thesis, Ecole Polytechnique de Montreal, Montréal, Canada, 2016, in French.

[46] K. H. Yang and C. N. Liu, "Finite element analysis of earth pressures for narrow retaining walls," Journal of GeoEngineering, vol. 2, no. 2, pp. 43-52, 2007.

[47] P. Yang, L. Li, and M. Aubertin, "Theoretical and numerical analyses of earth pressure coefficient along the centerline of vertical openings with granular fills," Applied Sciences, vol. 8, no. 10, p. 1721, 2018.

[48] J. Godbout, B. Bussière, M. Aubertin, and T. Belem, "Evolution of cemented paste backfill saturated hydraulic conductivity at early curing time," in Proceedings of the 60th Canadian Geotechnical Conference, pp. 2230-2236, Ottawa, Canada, October 2007.
[49] M. Aubertin, B. Bussiere, and R. P. Chapuis, "Hydraulic conductivity of homogenized tailings from hard rock mines," Canadian Geotechnical Journal, vol. 33, no. 3, pp. 470-482, 1996.

[50] B. Bussière, "Colloquium 2004: hydrogeotechnical properties of hard rock tailings from metal mines and emerging geoenvironmental disposal approaches," Canadian Geotechnical Journal, vol. 44, no. 9, pp. 1019-1052, 2007.

[51] G. Liu, L. Li, X. Yang, and L. Guo, "Numerical analysis of stress distribution in backfilled stopes considering interfaces between the backfill and rock walls," International Journal of Geomechanics, vol. 17, no. 2, article 06016014, 2017.

[52] N. Sivakugan, S. Widisinghe, and V. Z. Wang, "Vertical stress determination within backfilled mine stopes," International Journal of Geomechanics, vol. 14, no. 5, article 06014011, 2014.

[53] J. B. Dalcé, L. Li, and P. Y. Yang, "Experimental study of uniaxial compressive strength (UCS) distribution of hydraulic backfill associated with segregation," Minerals, vol. 9, no. 3, p. 147, 2019.

[54] Y. Potvin, E. G. Thomas, and A. B. Fourie, Handbook on Mine Fill, Australian Centre for Geomechanics (ACG), Perth, Australia, 2015.

[55] P. Y. Yang and L. Li, "Evolution of water table and pore-water pressure in stopes with submerged hydraulic fill," International Journal of Geomechanics, vol. 17, no. 9, article 04017052, 2017.

[56] R. P. Chapuis, "Numerical modeling of reservoirs or pipes in groundwater seepage," Computers and Geotechnics, vol. 36, no. 5, pp. 895-901, 2009.

[57] F. Ben Abdelghani, M. Aubertin, R. Simon, and R. Therrien, "Numerical simulations of water flow and contaminants transport near mining wastes disposed in a fractured rock mass," International Journal of Mining Science and Technology, vol. 25, no. 1, pp. 37-45, 2015.

[58] L. Li and M. Aubertin, "Limit equilibrium analysis for the design of backfilled stope barricades made of waste rock," Canadian Geotechnical Journal, vol. 48, no. 11, pp. 1713-1728, 2011.

[59] P. Yang, L. Li, M. Aubertin, M. Brochu-Baekelmans, and S. Ouellet, "Stability analyses of waste rock barricades designed to retain paste backfill," International Journal of Geomechanics, vol. 17, no. 3, article 04016079, 2017.

[60] S. Helwany, Applied Soil Mechanics with ABAQUS Applications, John Wiley \& Sons, Hoboken, NJ, USA, 2007.

[61] K. Terzaghi, Theoretical Soil Mechanics, Wiley, Hoboken, NJ, USA, 1943.

[62] K. Terzaghi, R. B. Peck, and G. Mesri, Soil Mechanics in Engineering Practice, John Wiley \& Sons, Hoboken, NJ, USA, 3rd edition, 1996. 


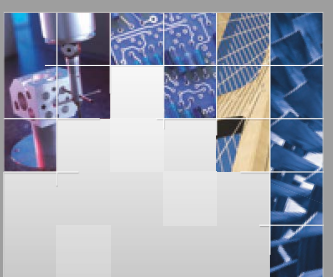

\section{Enfincering}
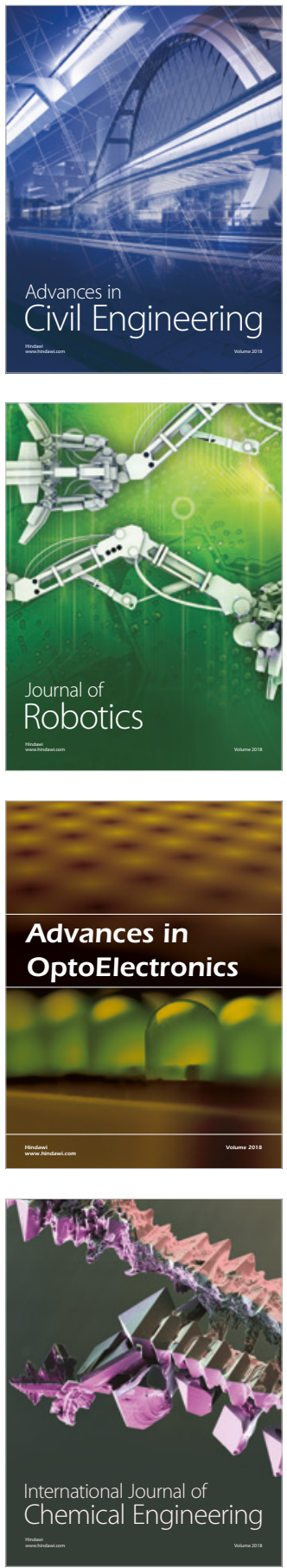

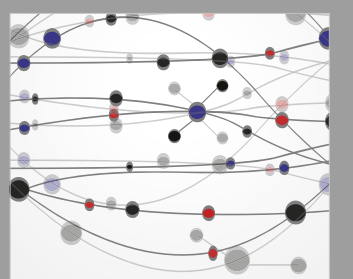

\section{Rotating \\ Machinery}

The Scientific World Journal

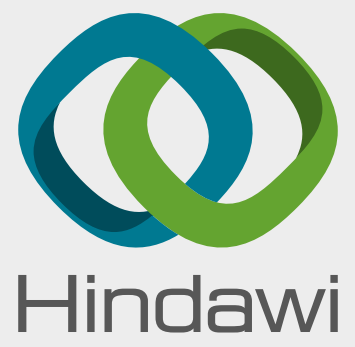

Submit your manuscripts at

www.hindawi.com
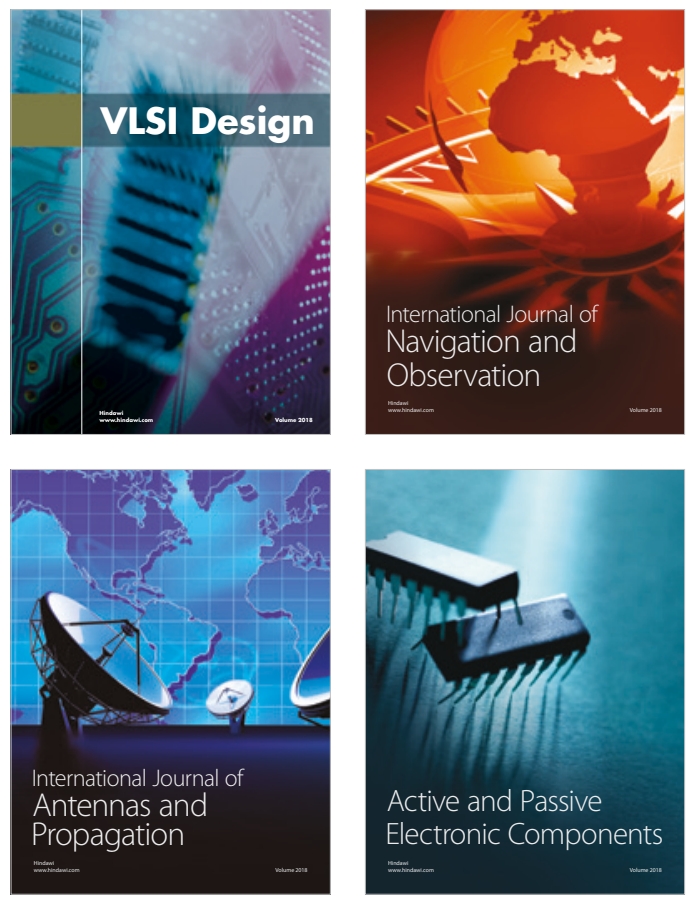
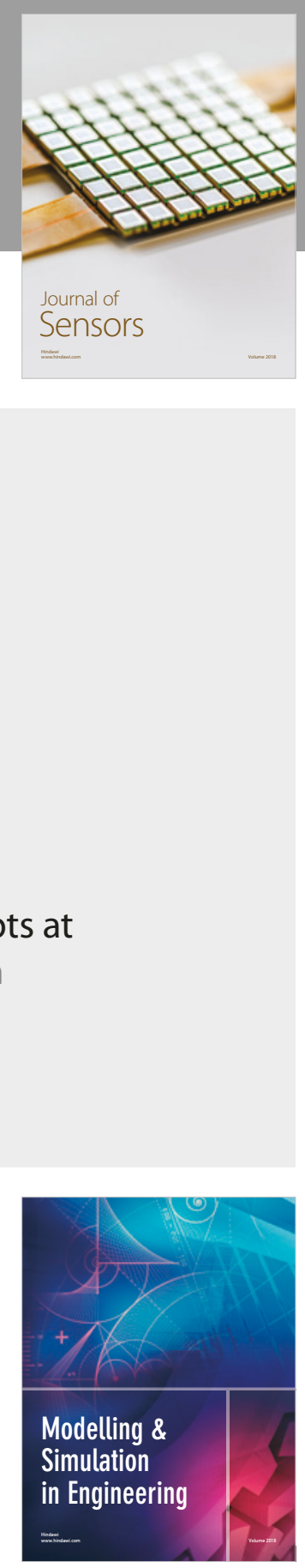

\section{Advances \\ Multimedia}
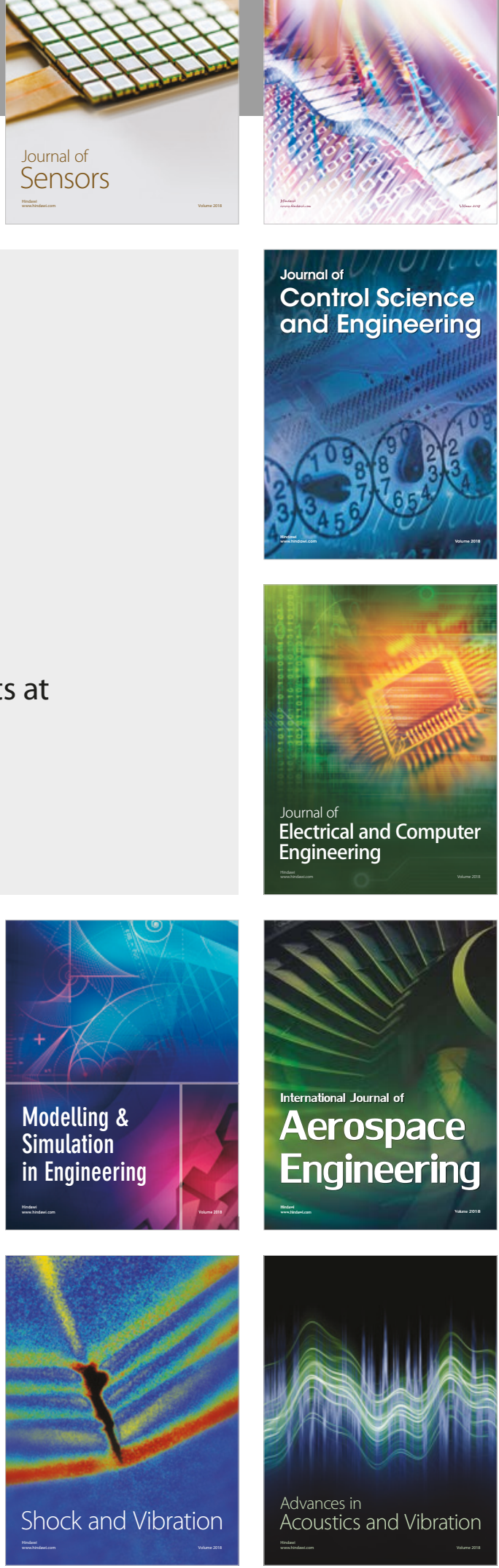